\title{
Brain Imaging and Behavior
}

\section{Neural correlates of correct and failed response inhibition in heavy versus light social drinkers: an fMRI study during a Go/No-go task by healthy participants

\author{
--Manuscript Draft--
}

Manuscript Number:

Full Title:

Article Type:

Keywords:

Corresponding Author:
BIOR-D-16-00121R2

Neural correlates of correct and failed response inhibition in heavy versus light social drinkers: an fMRI study during a Go/No-go task by healthy participants

\section{Original Research}

Social Drinking; alcohol; functional magnetic resonance imaging; go/no-go task; cognitive control; Error awareness

Salvatore Campanella

Université Libre de Bruxelles (ULB)

Brussels, BELGIUM

\section{Corresponding Author Secondary}

Information:

Corresponding Author's Institution:

Université Libre de Bruxelles (ULB)

\section{Corresponding Author's Secondary} Institution:

\section{First Author:}

Salvatore Campanella

First Author Secondary Information:

Order of Authors:

\begin{tabular}{|l|}
\hline Salvatore Campanella \\
\hline Julie Absil \\
\hline Carina Carbia Sinde \\
\hline Elisa Schroder \\
\hline Philippe Peigneux \\
\hline Mathieu Bourguignon \\
\hline Mathieu Petieau \\
\hline Thierry Metens \\
\hline Mustapha Nouali \\
\hline Serge Goldman \\
\hline Guy Cheron \\
\hline Paul Verbanck \\
\hline Xavier Detiège \\
\hline
\end{tabular}

Order of Authors Secondary Information:

Funding Information:

FRS-FNRS, Belgium (Research Grant J.0009.13)

Dr Salvatore Campanella

\section{Abstract:}

The ability to suppress responses that are inappropriate, as well as the mechanisms monitoring the accuracy of actions in order to compensate for errors, is central to human behavior. Neural alterations that prevent stopping an inaccurate response, combined with a decreased ability of error monitoring, are considered to be prominent features of alcohol abuse. Moreover, (i) alterations of these processes have been reported in heavy social drinkers (i.e. young healthy individuals who do not yet exhibit a state of alcohol dependence); and (ii) through longitudinal studies, these alterations have been shown to underlie subsequent disinhibition that may lead to future alcohol use disorders. In the present functional magnetic resonance imaging study, using a contextual Go/No-go task, we investigated whether different neural networks 
subtended correct inhibitions and monitoring mechanisms of failed inhibitory trials in light versus heavy social drinkers. We show that, although successful inhibition did not lead to significant changes, neural networks involved in error monitoring are different in light versus heavy drinkers. Thus, while light drinkers exhibited activations in their right inferior frontal, right middle cingulate and left superior temporal areas; heavy drinkers exhibited activations in their right cerebellum, left caudate nucleus, left superior occipital region, and left amygdala. These data are functionally interpreted as reflecting a "visually-driven emotional strategy" vs. an "executive-based" neural response to errors in heavy and light drinkers, respectively. Such a difference is interpreted as a key-factor that may subtend the transition from a controlled social heavy consumption to a state of clinical alcohol dependence. 


\section{Uhis \\ UNIVERSITE LIBRE DE BRUXELLES}

FACULTE DE MEDECINE

LABORATOIRE DE PSYCHOLOGIE MEDICALE ET D'ADDICTION
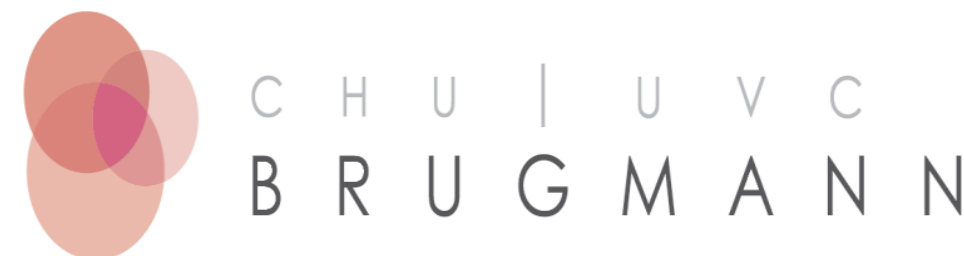

Brussels, 20th October 2016

Dear Professor,

Please find a second revised version of the manuscript entitled "Neural correlates of correct and failed response inhibition in heavy versus light social drinkers: an fMRI study during a Go/No-go task by healthy participants ", by Campanella and colleagues

We would like to thank you and the reviewers for the thorough review of our work, which helped us a lot in improving the quality of the manuscript.

Yours sincereley,

Salvatore Campanella, Phd

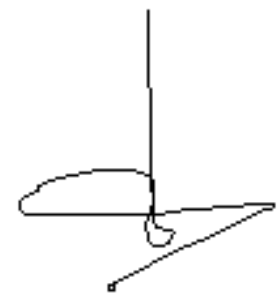


We would like to thanks both reviewers for their thorough job which helped us a lot to enhance the quality of our manuscript.

Reviewer 1: The Authors have addressed all of the issues i had raised very well. The manuscript is now ready for publication and I'm sure it will be a very good contribution to the literature.

Thanks.

Reviewer 2: The authors have been very responsive and have successfully addressed reviewer comments. I have a few minor suggestions: to add p-values to the captions of Figures 2 and 3. Also, it would be helpful to provide $x$ and $y$ coordinates for sagittal and coronal views (probably easiest in the Figures but could also be described in the captions). I believe that the revised manuscript will be very useful in the future studies of subjects spanning the full range of drinking.

Thanks. Captions of Figures 2 and 3 were modified accordingly. Adding $x, y, z$ coordinates on Figures 2 and 3 could be a bit redundant, as these data are already displayed in Tables 3 and 4 . Therefore, we suggest the readers to find these details on corresponding tables. 


\title{
Neural correlates of correct and failed response inhibition in heavy versus light social drinkers: an fMRI study during a Go/No-go task by healthy participants
}

\author{
Salvatore CAMPANELLA ${ }^{1}$, Julie ABSIL $^{2}$, Carina CARBIA SINDE ${ }^{3}$, Elisa \\ SCHRODER $^{1}$, Philippe PEIGNEUX ${ }^{4}$, Mathieu BOURGUIGNON ${ }^{5,6}$, Mathieu \\ PETIAU $^{7}$, Thierry METENS ${ }^{2}$, Mustapha NOUALI ${ }^{2}$, Serge GOLDMAN ${ }^{5}$, Guy \\ CHERON $^{7}$, Paul VERBANCK ${ }^{1}$, Xavier DE TIEGE ${ }^{5}$ \\ ${ }^{1}$ Laboratoire de Psychologie Médicale et d'Addiction, ULB Neuroscience Institute (UNI), Université \\ Libre de Bruxelles (ULB), Belgium \\ ${ }^{2}$ Department of Radiology, ULB-Hôpital Erasme, Université Libre de Bruxelles (ULB), Brussels, \\ Belgium \\ ${ }^{3}$ Department of Clinical Psychology and Psychobiology, University of Santiago de Compostela, \\ Galicia, Spain \\ ${ }^{4}$ Neuropsychology and Functional Neuroimaging Research Unit (UR2NF) at Centre de Recherches en \\ Cognition et Neurosciences (CRCN), ULB Neuroscience Institute (UNI), Université Libre de Bruxelles \\ (ULB), Brussels, Belgium \\ ${ }^{5}$ Laboratoire de Cartographie fonctionnelle du Cerveau, ULB Neuroscience Institute (UNI), Université \\ Libre de Bruxelles (ULB), Brussels, Belgium \\ ${ }^{6}$ BCBL, Basque Center on Cognition, Brain and Language, San Sebastian, Spain \\ ${ }^{7}$ Laboratory of Neurophysiology and Movement Biomechanics, ULB Neuroscience Institute (UNI), \\ Université Libre de Bruxelles (ULB), Brussels, Belgium
}

Abbreviated form of the title:

Number of words of the abstract: 250

Number of words of the text: 7468

Number of tables: 4

Number of figures: 3

All correspondence should be sent to: Salvatore Campanella, $\mathrm{PhD}$, Research Associate, The Belgian Fund for Scientific Research (F.N.R.S.), CHU Brugmann, Psychiatry Secretary 4, Place Vangehuchten - B-1020 Brussels, Belgium Tel: +32 24773465 - Email: salvatore.campanella@chu-brugmann.be or salvatore.campanella@ulb.ac.be 


\section{Abstract}

The ability to suppress responses that are inappropriate, as well as the mechanisms monitoring the accuracy of actions in order to compensate for errors, is central to human behavior. Neural alterations that prevent stopping an inaccurate response, combined with a decreased ability of error monitoring, are considered to be prominent features of alcohol abuse. Moreover, (i) alterations of these processes have been reported in heavy social drinkers (i.e. young healthy individuals who do not yet exhibit a state of alcohol dependence); and (ii) through longitudinal studies, these alterations have been shown to underlie subsequent disinhibition that may lead to future alcohol use disorders. In the present functional magnetic resonance imaging study, using a contextual Go/No-go task, we investigated whether different neural networks subtended correct inhibitions and monitoring mechanisms of failed inhibitory trials in light versus heavy social drinkers. We show that, although successful inhibition did not lead to significant changes, neural networks involved in error monitoring are different in light versus heavy drinkers. Thus, while light drinkers exhibited activations in their right inferior frontal, right middle cingulate and left superior temporal areas; heavy drinkers exhibited activations in their right cerebellum, left caudate nucleus, left superior occipital region, and left amygdala. These data are functionally interpreted as reflecting a "visually-driven emotional strategy" vs. an "executive-based" neural response to errors in heavy and light drinkers, respectively. Such a difference is interpreted as a key-factor that may subtend the transition from a controlled social heavy consumption to a state of clinical alcohol dependence.

Keywords: Social Drinking; Alcohol; Functional magnetic resonance imaging; Go/No-go task; Cognitive control; Error awareness 


\section{Introduction}

Drug addiction is clearly linked with several deficient cognitive processes indexed by abnormal neural functioning (reviewed by Rogers and Robbins, 2001). It is well established that alcohol neurotoxicity from chronic alcohol dependence results in deleterious effects on the central nervous system, such as brain atrophy or dysfunction. This is thought to be mainly due to specific neurodegenerative mechanisms, inducing neuronal loss as well as brain structural and functional alterations (Crews et al., 2005). Moreover, these brain impairments correlate with the lifetime dose of ethanol consumed (Nicolas et al., 1997). Aside from these clear-cut effects induced by long-term heavy consumption, neuroimaging data also suggest that even minor cognitive restrictions can represent biological predictors of future alcohol abuse. There is indeed evidence suggesting that baseline decreased activity, or higher neural resources needed to achieve some specific cognitive functions, can predict substance use disorder in adolescence (Goldstein et al., 2001). For instance, by functional magnetic resonance imaging (fMRI) during a Go/No-go task it was shown youths with a family history of alcoholism displayed less frontal activity during response inhibition than did controls. This suggests that this altered neural activity may underlie subsequent disinhibition, potentially leading to future alcohol use disorders (Schweinsburg et al., 2004). Similarly, through longitudinal Go/No-go fMRI studies it was shown that future heavy drinkers exhibited less activation of the inhibitory circuitry (Norman et al., 2011; Wetherill et al., 2013), as well as less activity during performance monitoring (Smith and Mattick, 2013) before the onset of heavy drinking, thus suggesting that neural vulnerabilities may exist prior to the onset of alcohol abuse. These prior brain vulnerabilities are of the highest relevance, as the initiation of excessive alcohol consumption will, due to substance neurotoxicity, lead 
to additional alterations in brain functioning. All up, this may explain why anomalies displayed in heavy social drinkers can quickly mirror those observed in alcohol dependence (Petit et al., 2014 for a review), and why they are associated with an increased risk of subsequent long-lasting alcohol dependence (Chassin et al., 2002; Bonomo et al., 2004; Viner and Taylor, 2007). Heavy consumption is, however, not yet equivalent to dependence. The deficits are either less serious than those observed in alcoholism or, while they may be detectable by neuroimaging tools, they remain unexpressed at the behavioural level (reviewed by Hermens et al., 2013). It is therefore important to emphasize the need for more education in regard to the dangers of heavy social drinking, and for reconsideration of standard practices used to market alcohol to young people (Smith and Foxcroft, 2009), in order to avoid the potential of triggering the transition that leads from an excessive, but "controlled", consumption to a state of dependence.

While there have been several fMRI studies to date that have been able to link heavy social drinking with a decreased performance in various cognitive tasks (Squeglia et al., 2011, 2012; Xiao et al., 2013), most studies in this regard obtained evidence of neural differences without any behavioral modification or indexing compensation mechanisms (Schweinsburg et al., 2010; 2011; Campanella et al., 2013). This was also true when techniques other than fMRI, such as event-related potentials, were used (Ehlers et al., 2007; Crego et al., 2009, 2010, 2012; LopezCaneda et al., 2012; Maurage et al., 2009; 2012; Petit et al., 2012). The main aim of the present fMRI study was to compare the neural networks activated in heavy vs. light social drinkers (i.e. in healthy participants who do not exhibit an alcohol dependence) during a Go/No-go task when they perform equal successful and unsuccessful inhibitions. 
The ability to withhold inadequate responses (e.g., laughing during a funeral) is central to human behavior. Response inhibition (RI) is considered to be a key component of executive control, as it refers to the ability to suppress responses that are no longer required or contextually inappropriate, supporting flexible goal-directed behavior in ever-changing environments, and allowing individuals to recover from potentially harmful situations before it is too late (Verbruggen and Logan, 2009). However, when inhibition fails, registering the unwanted self-generated outcome is the first step to be able to adjust one's own actions (Vocat et al., 2008). In this view, error detection (ED) is among the highest evolved human self-monitoring functions (Rubia et al., 2003; Ridderinkhof et al., 2004). A vast set of experimental studies has been devoted to both processes, indicating that a complex neural circuit involving both cortical (such as the inferior frontal cortex (IFC) and the pre-supplementary motor area (pre-SMA)) and subcortical regions (e.g. basal ganglia structures) allow for the successful inhibition of a prepotent motor response (reviewed by Bari and Robbins, 2013), while the dorsal anterior cingulate cortex (dACC) plays a central role in signaling the occurrence of conflicts in information processing, thereby triggering compensatory adjustment mechanisms (reviewed by Botvinick et al., 2004).

Overall, on the one hand, neural alterations to RI prevent stopping of a prepotent response (e.g. drug consumption). On the other hand, a decreased ability of ED, also called "error awareness" (Garavan and Stout, 2005), which function is to lead to optimization of behavioral responses, appeared as a main feature subtending the continuation of the addictive behavior. Altogether, simultaneous deficits of RI and ED may trigger the onset and the persistence of alcohol abuse despite repeatedly negative consequences (reviewed by Volkow et al., 2004; Luijten et al., 2014). Moreover, while some studies reported no impact of alcohol-related context on 
correct/failed inhibitions (Nederkoorn et al., 2009; Houben et al., 2012; Mainz et al., 2012; Petit et al., 2014), others have shown higher commission error rates, as alcoholrelated cues are supposed to grab attention and decrease inhibitory skills (Greeley et al., 1993; Cox et al., 1999; Herrmann et al., 2001; Noël et al., 2005; Bartholow et al., 2007; 2010; Stacy and Wiers, 2010). With this in mind, three main questions will be investigated in the present study. Firstly, we aim to examine how context can modulate the inhibitory performance of light vs. heavy social drinkers. To achieve this aim, we used a variant of the Go/No-go task, in which Go and No-go trials were displayed on long-lasting background contexts (neutral (NC), alcohol-related (AC), non-alcohol-related (NAC)). Indeed, controlling drinking behavior within long-term affective situations is often required, and behavioral and neural reactions provoked by short-duration stimuli are clearly not as intense or complex as those generated by longer emotional contexts (Carretié et al., 2006; Albert et al., 2010). Such a "contextual Go/No-go task" has already been used in our laboratory with social drinkers during an ERP recording (Petit et al., 2012) In that study, behavioral results disclosed no main group effect, but a marginal significant interaction group $\mathrm{x}$ context $(p=0.082)$, as heavy drinkers had a similar amount of commission errors independent of contexts (between 20-22\%), while light drinkers exhibited fewer commission errors in AC than in NAC and NC (15\% vs. 18-19\%). Interestingly, when confronted with the same task, recently detoxified alcoholic patients disclosed more commission errors than matched controls, but independently of the context (mean of $22 \%$ vs. $11 \%$ ) (Petit et al., 2014). Given these contradictory results, we decided to investigate potential differences in neural networks involved when heavy and light social drinkers have to perform inhibition on alcohol or non-alcohol related contexts. Secondly, we expected that, independently of contexts, by controlling for some 
individual personality factors that are well-known to influence inhibitory skills (such as impulsivity for instance; Noël et al., 2005), heavy and light social drinkers would perform the task similarly (as in Wetherill et al., 2013). This would allow us to compare a same amount of successful trials between groups. We hypothesized that even in the absence of group behavioral differences; heavy drinkers would recruit a different neural network as compared to light drinkers to achieve successful inhibitions, as was found to be the case in a previous study of ours when both groups performed equally well in a short-term verbal memory N-back task (Campanella et al., 2013). Thirdly, keeping in mind what was said in regard to correct inhibitory trials, the same logic may be applied to failed trials, as we expected that, for the same amount of commission errors, light and heavy drinkers will disclose a different neural network to monitor their errors.

\section{Materials and Methods}

\section{Participants}

First of all, a general screening of 150 students from the Faculty of Psychology at the University of Brussels (Belgium) was conducted in order to ascertain patterns of alcohol consumption. For this purpose, students filled in a questionnaire assessing their alcohol-drug consumption behavior as well as personal data and psychological parameters. On the basis of these self-reported data, groups of participants were defined as detailed below. Exclusion criteria for participants included major medical issues, conditions relating to impairment of the central nervous system (including epilepsy and a prior history of brain injury), visual impairments, and past or current drug consumption (other than alcohol and tobacco use). Our main objective was to select two groups of participants who only displayed 
differences in terms of their alcohol-drinking pattern (see Table 1 for complete descriptive data). Since there was a high co-occurrence of excessive drinking and substance use, such as cannabis and tobacco (Hall, 1970; Campbell et al., 1971), subjects concurrently consuming cannabis (defined as at least once in the month prior to the study) were not included. Also, a similar number of participants with a family history of alcoholism (FHA) (McGue, 1994) were included in the final groups. The Alcohol Use Disorder Identification Test (AUDIT) was used to evaluate participants in regard to hazardous drinking, harmful drinking, or alcohol dependence (Saunders et al., 1993). AUDIT scores were used to include participants in light versus excessive social drinker groups. Participants were only classified as heavy drinkers if their score on the AUDIT was equal to or above the cut-off score of 8 , which is an indicator of hazardous drinking (Babor and Higgins-Biddle, 2001), while they were considered to be light drinkers if they scored a 7 or lower (Field et al., 2008). This classification was confirmed utilizing the AUDIT-C consumption subscore, which is defined by three items of the complete 10-items AUDIT instrument, and which can help identify people who are hazardous drinkers (Bush et al., 1998). The AUDIT-C is scored on a scale $0-12$. A score of 3 for women and 4 for men is considered optimal for identifying hazardous drinkers; the higher the score, the more likely drinking pattern affects participants' safety (Bradley et al., 2003). Participants were also asked to report the mean number of alcohol doses (one dose corresponding to 10 grams of pure ethanol) they consumed in a week during the last six months ("In the last six months, how many drinks do you consume in a week in general?"). Hazardous drinking, which can significantly impact public health despite the absence of any bona fide disorder in the individual users, is defined as a level of alcohol consumption likely to result in harm to the user or other individuals (Babor et al., 1994). 
In order to ensure that any potential difference in the fMRI data would be due to alcohol consumption and not to other variables, groups were balanced for righthandedness (assessed with the Edinburgh scale (Oldfield, 1971)), age, gender, and level of education (i.e. the number of years of education completed since starting primary school). Participants were also asked to fill out questionnaires assessing psychological measures. These were the State-Trait Anxiety Inventory (STAI A and B) to assess state and trait anxiety (Spielberger et al., 1983); the Liebowitz Social Anxiety Scale (LSAS) to assess social anxiety (Liebowitz, 1987); the Beck Depression Inventory (BDI) to assess depression (Beck and Steer, 1987); and the Urgency Premeditation Perseverance and Sensation seeking impulsive behavior scale (UPPS; Whiteside et al., 2003), which is a measure of impulsivity as a personality trait. The UPPS is composed of subscales, one of which describes the difficulty to restrain behavioral reactions in situations that elicit strong emotions (Urgency) (Cirilli et al., 2011). The control of all of these variables is important, as young drinkers with depression, generalized or social anxiety, as well as high impulsivity symptoms have been shown to be at increased risk of AUD during young adulthood (McKenzie et al., 2011; Norberg et al., 2011; Henges and Marczinsky, 2012). Therefore, we can observe that participants of both groups disclosed no difference in terms of these variables (see Table 1).

Based on these criteria, 40 undergraduate students were selected for the fMRI study, and they were classified as light $(n=20)$ or heavy social drinkers $(n=20)$. We obtained informed written consent from the participants after they were fully informed regarding the nature of the study. The local ethics committee of the Brugmann Hospital approved the study ("Comité d'Ethique Hospitalier OM 026”). The participants were instructed to abstain from consuming alcohol 24 hours prior to the 
fMRI sessions, and none of them reported any drinking episodes in the two days prior

to the assessment. Alcohol abstinence before the test was confirmed using AlcoSensor III breath analyzers Alcometer (Alert J5®, Alcohol Countermeasure Systems Corp, 2006), and their urine was tested to control for cannabis use (Tetrahydrocannabinol; Instant-View ${ }^{\circledR}$ MultiDrug Screen Urine Test; Alfa Scientific Designs, Inc.) in the light as well as in the heavy drinkers. Participants were paid 50 euros for their time.

Among these participants, four were found to have reaction times in response to Go trials that were too slow ( 3 s.d. above the mean): they were therefore discarded from final analyses. Among the remaining 36 participants, two (one in each group) were identified as ambidextrous (Robinson, 2013): after running SPM analyses without them, we observed that their inclusion did not affect the laterality of observed brain activations. Therefore, these 36 participants were included in the final sample used for the statistical analyses, with 17 and 19 participants in the light and in the heavy social drinker groups, respectively.

Insert Table 1 about here

\section{The Go/No-go task}

Participants were instructed to press a button with the thumb of their right hand, as fast and as accurately as possible, whenever the letter M (Go) was displayed, and to withhold pressing the button when the letter W (No-Go) was displayed. Responses were made on a commercially available MRI compatible keypad system (fORP; Current Design, Vancouver). Both letters were superimposed on pictorial backgrounds, denoting three different contexts: the neutral context (NC), represented by a black screen; the alcohol-related context (AC), represented by someone holding a glass of beer; and the non-alcohol context (NAC), represented by an empty basket. 
Two fMRI recording sessions were performed. During each session, the order of the three stimulation blocks (NC, AC, and NAC) was similar in Sessions 1 and 2, and this order was counterbalanced across participants. Each block contained 133 letters, divided into 93 Go (70\%) and 40 No-Go (30\%) letters. Go and No-Go letters were displayed in a semi-random order to avoid the consecutive presentation of two No-Go letters within each block. Each block started with the presentation of a background screen (black for $\mathrm{NC}$, or $\mathrm{AC}$ or $\mathrm{NAC} ; 500 \mathrm{~ms}$ ) followed by the letter $\mathrm{M}$ or $\mathrm{W}$ appearing on this background screen for $200 \mathrm{~ms}$, subsequently replaced by a return to the initial background screen for $1,300 \mathrm{~ms}$. Thus, the subjects had up to $1,500 \mathrm{~ms}$ to press the button before the next letter appeared. An interval of 1 minute was taken between each block during a Session; a five minute interval was allowed between Sessions 1 and Session 2. Additional details concerning the task can be found in Petit et al. (2012) (see Figure 1 for illustration).

Insert Figure 1 about here

\section{Procedure}

\section{Behavioral statistical analysis}

Behavioral data were analyzed with repeated measures (ANOVA). Omission error rates (i.e. no response in Go trials), commission error rates (i.e. a key press in No-Go trials), and reaction time (RT) to Go stimuli were analyzed. Simple effects were explored and interaction sources were systematically examined. The Students' ttests, ANOVA, and Bonferroni's post-hoc test were used when appropriate. All analyses were done with SPSS $20^{\circledR}$, and the level of significance was set at 0.05 .

fMRI data acquisition and image analysis

Data were acquired on a Philips Achieva 3T (Philips HealthCare, Best, the Netherlands) using a dynamic axial T2*-sensitive gradient-echo (EPI) sequence 
(TR=3,000 ms (=dynamic scan time); TE=35 ms; flip angle 90; FOV 230 (RL) x 230

(AP) $\mathrm{mm}^{2}$; SENSE acceleration factor 2.9; matrix size 76 x 75; acquisition voxel size: $3.03 \times 3.03 \times 3 \mathrm{~mm}^{3}$ ). For each dynamic volume, a total of 40 contiguous transverse slices were acquired in an interleaved order. Each fMRI session included 220 BOLD volumes and lasted around 12 minutes. Two fMRI sessions were achieved as two consecutive BOLD scans. Anatomical images were obtained using a sagittal 3D T1weighted TFE sequence with an inversion prepulse (TR/TE=9.8/4.6 ms; TI 1,035 ms; TFE shot acquisition: 1,950ms; flip angle $8^{\circ}$; FOV: 200 (FH) x 238 (AP) $\mathrm{mm}^{2}$; matrix size: $228 \times 200$; acquisition voxel size: $0.88 \times 1.19 \times 1.0 \mathrm{~mm}^{3}$; total acquisition time 5min35s). The MR scanner was equipped with the Quasar Dual imaging gradients (maximum amplitude and slew rate: $40 \mathrm{mT} / \mathrm{m}$ and $200 \mathrm{mT} / \mathrm{m} / \mathrm{ms}$ ) and an 8 -channel SENSE head coil.

Functional MRI data were pre-processed and analyzed with SPM8 (Wellcome Department of Cognitive Neurology, London) implemented in MATLAB 7.8 (Mathworks Inc., Sherbom, MA). All the following steps were based on these main following references: Holmes et al., 1997; Friston et al., 1998; 2005. The first five functional volumes in the acquisition were discarded to avoid transient spin saturation effects. Preprocessing for each individual required that functional images were (i) corrected for slice acquisition delays, (ii) realigned to the first volume of the first run to correct for within- and between-run motion, (iii) co-registered with the anatomical scan, (iv) normalized to the MNI template using an affine fourth degree $\beta$-spline interpolation transformation and a voxel size of $2 \times 2 \times 2 \mathrm{~mm}^{3}$ after the skull and bones had been removed with a mask based on the individual anatomical images, and (v) spatially smoothed using a 8-mm full width at half maximum (FWHM) Gaussian kernel. All included subjects had less than $4 \mathrm{~mm}$ of head movement in $x, y$, or $z$ 
directions (a threshold usually reported in fMRI studies literature; e.g., Massat et al., 2012; Murphy et al., 2012). Additionally, it is also current practice (in order to minimize the influence of motion artifacts on group comparisons) to conduct a matching of within scanner movements between groups (e.g., Schillbach et al., 2016). Therefore, the magnitude of head motion at each time point for translation and rotation parameters was obtained for each subject in each session, and averaged within each group. No between-groups difference $(p>.05)$ was evidenced using either the maximum head motion or the mean head motion measurements, indicating similar movement patterns during scanning.

Data were analyzed using a mixed-effects model that aimed to show a stereotypical effect in the population from which the subjects were drawn (Penny and Holmes, 2003). For each subject, a first-level intra-individual analysis was aimed at modeling data to partition observed neurophysiological responses into components of interest, confounds, and error, by using a general linear model (Friston, 2003). For each subject, evoked hemodynamic responses to each event types were modeled with a delta (stick) function corresponding to stimulus presentation (with an explicit duration set to 0 ) convolved with a canonical hemodynamic response function within the context of the general linear model (GLM) (e.g., Jacques et al., 2009). Correct and incorrect responses were modeled separately (e.g., Strange et al., 2005). More precisely, the regressors of interest were built using stick functions separately positioned at the onset of each correct No-go trial (correct No-go trials in NC, AC, NAC) as well as at the onset of all Errors (modeled separately and identified at each button click for the letter "W"). The errors were considered altogether, independently of contexts, due to their small rate (average number of 5.6 to 8.4 errors on 40 trials by context and by session). Movement parameters derived from realignment of the 
functional volumes (translations in $\mathrm{x}, \mathrm{y}$ and $\mathrm{z}$ directions and rotations around $\mathrm{x}, \mathrm{y}$ and regressors were secondarily convolved with the canonical hemodynamic response function. High-pass filtering was implemented in the matrix design using a cut-off period of 128 seconds to remove low drift frequencies from the time series. The two fMRI sessions were modeled separately. Effect of interests were then tested by linear contrasts, generating statistical parametric maps $[\mathrm{SPM}(\mathrm{T})]$. Here, the contrasts of interest searched for significant changes in blood oxygen level-dependent (BOLD) signal associated with correct and incorrect No-go trials (correct No-go trials in NC, AC, and NAC, and all Errors) in both fMRI sessions. Since no inference was made at this fixed effect level of analysis, summary statistic images were thresholded at $p<$ 0.95 (uncorrected). Resulting subject-level contrast images were then spatially smoothed at $6 \mathrm{~mm}$ FWHM Gaussian kernel (Peigneux et al., 2006), and entered in two separate second-level factorial analyses; one for correct trials (correct trials in $\mathrm{NC}$, in $\mathrm{AC}$ and in NAC) and the other one for failed trials (Errors), in which subjects were considered as a random effect (RFX). This second smoothing procedure was performed to increase inter-subject averaging at the group level, taking into account inter-individual anatomical variability. As parameters estimation, contrasts and smoothing are all linear operations, smoothing at the second level permits the overall smoothing kernel to increase in a linear manner. This improves statistical power at the group level while allowing spatially accurate results at the first level (e.g., Boly et al., 2007).

Our first two questions concerned correct inhibitory trials. The first one concerns the impact of different contexts on correct inhibitions, while the second one refers to the neural activity related to correct inhibitions, independently of contexts. 
Similarly to analyses computed on behavioral results, these two questions could be investigated through a full factorial design 2 (Light vs. Heavy) x 3 (NC, AC, NAC), computed to show T-contrasts testing for significant activation changes between groups, for the main effects of contexts and groups $\mathrm{x}$ contexts interactions. A null conjunction analysis was also computed to identify the brain network commonly activated when trials were correctly inhibited at the group level $(\mathrm{N}=36)$, independently of context.

Our third question concerned the neural activity related to failed inhibitions, independently of contexts. Due to the small error rate by context, it was impossible to carry on the full factorial design 2 (Light vs. Heavy) x 3 (NC, AC, NAC). We hence computed a one-sample t-test to assess the neural network related to Errors across all participants $(\mathrm{N}=36)$. Two-sample t-tests were then used to compare related activity in light vs. heavy drinkers.

To conclude, statistical inferences about our three main questions were then obtained after corrections at the voxel level using Gaussian random field theory (Worsley, 1996) at $\mathrm{p}^{\text {corr }}<0.05$ corrected for multiple comparisons in the whole brain volume.

\section{Results}

\section{Behavioral data}

Three main analyses were performed to analyze this task by way of an analysis of variance (ANOVA; 3 × 2 mixed factorial design) with 'Context' (NC, AC, NAC) as the within-subject factor and 'Group' (light; heavy) as the between-subject factor. The data are summarized in Table 2 . 
Firstly, we checked the speed of response (RTs) in the Go trials. The results did not reveal a main Group effect $(p=0.831)$ nor a Group x Context interaction $(p=$ $0.634)$, but a main effect of Context was observed $[\mathrm{F}(2,68)=8.607, p=0.001$; etasquared $=0.202$, observed power $=0.944$, suggesting that RTs in the Go trials during NC blocks were faster than during NAC ones (post hoc Bonferroni t-tests: NC Go vs. NAC Go: 322 vs. 334 ms, $p=0.002$; NC Go vs. AC Go: 322 vs. 330 ms, $p=0.063$; AC Go vs. NAC Go: 330 vs. 334 ms, $p=0.240)$.

We also examined whether both groups were equivalent in their performance in terms of responding to Go trials. No significant statistical group effect emerged ( $p$ $>0.175$ ), probably due to a ceiling effect (i.e. a mean performance of $99 \%$ correct in both groups).

The final analysis concerned commission errors, i.e. the rate of inhibition errors (the key press in No-go trials). A main effect of Context emerged $[\mathrm{F}(2,68)=5.679, p=0.007$; eta-squared $=0.143$, observed power $=0.813]$. Post hoc Bonferroni t-tests showed that the rate of errors is more substantial in NC compared to AC $(p=0.003)$ and NAC $(p=0.042)$, while AC and NAC did not differ $(p=1)$. However, the number of errors is not modulated by Group (main group effect: $\mathrm{F}(1.34)=1.698, p=0.201$; interaction Group x Context: $\mathrm{F}(2.68)=0.379, p=0.661)$, suggesting that the rate of commission errors is similar in light and heavy drinkers, irrespective of contexts.

Overall, the behavioral data suggested that light and heavy social drinkers performed the Go/No-go task equally, as indexed by a similar amount of correct inhibitions as well as of commission errors, irrespective of contexts (see Table 2). Importantly, hit rates on Go trials did not differ between groups. Indeed, it is wellknown that when participants tend to respond more rapidly, they also tend to exhibit 
decreased accuracy in No-go trials (Jonker et al., 2013). In the present study, however, the absence of group difference on commission errors did not seem to be due to a "protective" slowing of the RT in Go trials.

\section{Insert Table 2 about here}

\section{fMRI data}

(1) Is there an effect of context?

We computed a full factorial design 2 (Light vs. Heavy) x 3 (NC, AC, NAC) analysis. Firstly, we checked for specific activations related to correct No-go trials when each context was specifically envisaged on the whole sample $(\mathrm{N}=36)$. The NC context involved a widespread neural activity, including bilateral frontal inferior, right middle temporal regions, right angular and left inferior parietal regions. Activations of left-lateralized frontal inferior, angular, middle temporal, and frontal superior areas were disclosed during the AC context. In regard to the NAC context, activity was shown in bilateral angular regions, in bilateral inferior and left superior frontal areas, and left inferior temporal regions. When compared through T-contrasts for the whole sample, these contexts (NC vs. AC-NAC; AC vs. NC-NAC; NAC vs. NC-AC) did not reveal any supra-threshold results (neither for corrected $\mathrm{p}<0.05$ nor for uncorrected $\mathrm{p}<0.001$; cluster extent $\geq 100$ ). Similarly, looking at between-population differences for contexts (T-contrasts NC light vs. NC heavy; AC light vs. AC heavy; NAC light vs. NAC heavy; NC heavy vs. NC light; AC heavy vs. AC light; NAC heavy vs. NAC light) did not reveal any supra-threshold results (for corrected $\mathrm{p}<0.05$, as well as for uncorrected $\mathrm{p}<0.001$; cluster extent $\geq 100$ ). Lastly, a null conjunction analysis on the whole sample revealed that, independently of the type of contexts, correct inhibitions 
involve a neural network encompassing left angular and left inferior frontal regions across all participants (see Table 3 and Figure 2).

Insert Figure 2 and Table 3 about here

\section{(2) Are there any group differences for correct inhibitions?}

Based always on the full factorial design, when all correct trials were considered independently of the context, T-contrast looking at between-group differences (NCAC-NAC correct light vs. NC-AC-NAC correct heavy) did not reveal any suprathreshold results (for corrected $\mathrm{p}<0.05$ as well as for uncorrected $\mathrm{p}<.001$; cluster extent $\geq 100$ ) for the light or for the heavy drinkers.

\section{(3) Are there any group differences for failed inhibitions?}

A one sample t-test on all of the participants $(\mathrm{N}=36)$ revealed that, independently of the type of contexts (as the ratio of errors was too small in separate contexts to allow for specific analyses), failed inhibitions involve a widely distributed neural network involving right anterior cingulate, inferior frontal and inferior parietal regions as well as left superior temporal and angular areas (see Table 4 and Figure 3). Looking at between-population differences, our two sample t-test analysis disclosed a network of regions showing an increased BOLD response to failed trials which differed considerable for the groups. On the one hand, light drinkers displayed higher BOLD activity in the right inferior frontal, right middle cingulate, and left superior temporal regions. On the other hand, heavy drinkers exhibited higher BOLD activity in the left superior occipital, left caudate, left amygdale, and right cerebellum areas.

Insert Figure 3 and Table 4 about here 


\section{Discussion}

While there have been a few studies (Squeglia et al., 2011; Squeglia et al., 2012; Xiao et al., 2013) linking heavy social drinking with decreased performance, as compared to light drinkers, most studies using ERPs or fMRI found evidence for neural differences indexing compensation mechanisms, without any behavioral modification (reviewed by Petit et al., 2014). In the present study, we found that even though light and heavy drinkers displayed a similar performance level in a visual Go/No-go task, specific brain activations were detected, mainly for failed inhibitions, when groups were compared.

A first set of analyses allowed us to check for activations observable in all of the participants when they achieved correct RI in different contexts $(\mathrm{NC}, \mathrm{AC}$, and NAC). Any supra-threshold significant data were not seen when t-contrasts were performed between contexts (across all participants) nor when between-group differences were examined separately for each context. This suggests that, in our experiment, context is not strong enough to elicit BOLD signal modulation in light and heavy social drinkers.

A second set of analyses aimed at investigating whether, independently of context, correct inhibitions can elicit different brain activations in light versus heavy drinkers. A conjunction analysis revealed that, when they achieved correct inhibitions, all participants activated their left inferior frontal regions as well as their left angular gyrus. Activation of the right inferior frontal cortex (rIFC) has been consistently linked with RI (Aron et al., 2004; Chambers et al., 2009; Bari and Robbins, 2013), although the involvement of the left IFC has also been reported (Swick et al., 2008), indicating that sometimes activation has also been observed bilaterally (Menon et al., 2001; Watanabe et al., 2002; Cai and Leung, 2011). A role for the left angular gyrus 
cannot be directly associated with executive functioning. Rather, the left angular gyrus is known to be engaged in phonological short-term memory and mathematical problem solving. Participants may therefore at times have employed a verballymediated calculation strategy to respond to the Go/No-go task, instead of exerting executive control (Mahmood et al., 2013). Though yet again, light and heavy drinkers did not elicit different brain regions to achieve correct inhibitions. This could index a still efficient cognitive control mechanism, that could therefore be envisaged as a "protective factor against dependence". Indeed, despite their profile as heavy consumers of alcohol (i.e. a mean of $12 \pm 5.6$ alcohol doses per week), our participants cannot be considered as alcohol dependent patients, as suggested by a mean AUDIT score below the cut-off score of 20 (as AUDIT scores of above 20 clearly warrant further diagnostic evaluation for alcohol dependence; Babor et al., 1994) and the fact that recently detoxified alcoholic patients who were confronted to a similar task in our laboratory (Petit et al., 2014) disclosed a mean AUDIT score of 32.

The most important results of the present study were obtained, however, when failed inhibitions (independently of context) were considered. We were able to show that all participants activated a widely distributed neural network, involving the rACC, rIFC, right inferior parietal as well as left angular and left pole temporal superior (STS) regions, when they commit errors. Aside from activations already found with correct inhibitions, related to executive control (rIFC) and verbal strategy (left angular gyrus) processes, specific activations were also revealed across all of the participants when an error was committed. In this view, rACC activations are probably the well-documented ones. Indeed, a well-established finding is that the ACC transiently activates in association with the commission of errors (Botvinick et 
al., 2004), serving as a generic "error detector" (Braver et al., 2001) that may trigger compensatory adjustment mechanisms necessary to adjust one's own action (Vocat et al., 2008). Among the other activations, the inferior parietal lobe seems to be more involved in visual-spatial attention (Behrmann et al., 2004), while activation of left temporal regions has repeatedly been reported to occur in successive discrimination and temporal comparisons of simple visual attributes, as engaged in our visual Go/Nogo involving the discrimination of letter "M" and "W" (De Zubicaray et al., 2000), suggesting its implication in selective attention mechanisms (Stevens et al. 2000). Overall, when the failed inhibitions of all of the participants were considered, the data of the present study confirmed earlier results suggesting that IFC is a key brain region responsible for inhibitory motor control; while the mesial prefrontal cortex, including the ACC, in conjunction with the inferior parietal lobe, form a neural network for error detection (Rubia et al., 2003; 2005; 2007). Above all, by controlling for behavioral performance, the main relevance of the present study was that it allowed for comparison of the neural networks subtending a same amount of correct and failed inhibitions in light and heavy social drinkers. In this view, while neural differences between groups for correct inhibitions could not be discerned, the main results of the present study were in regard to BOLD group differences observed in response to failed inhibitions, as these differences were highly significant ( $\mathrm{p}$ corr $<0.05$, cluster extent $\geq 100$ ). Indeed, compared to heavy drinkers, light drinkers disclosed enhanced activations in the rIFC, right middle cingulate (rMCC) and the left STS during errors, while, inversely, heavy drinkers exhibited the most pronounced activations in the left occipital superior, left amygdale, and left caudate areas, as well as the right cerebellum. In other words, we observed that, while light and heavy drinkers committed the same number of errors, the underlying neural networks for these errors 
were entirely different. On the one hand, we were able to document that light drinkers exhibited activations in regions mediating response inhibition (rIFC; Chambers et al., 2009), motor response selection (rMCC; Braver et al., 2001) as well as in regions associated with the prediction of actions based on past actions (left STS; Choudhury et al., 2006). Indeed, the MCC, corresponding to the rostral cingulate motor area (Picard and Strick, 1996), is known to undergo enhanced activation during error processing (Braver et al., 2001; Garavan et al., 2003; Nee et al., 2011), triggering environmental monitoring and response selection mechanisms (Taylor et al., 2009). On the other hand, we were able to document that heavy social drinkers exhibited activations in regions devoted to movement control (as cerebellar activity has been linked to the processing of error signals that could be used for improving performance; Ernst et al., 2002), to pro-active slowing (as the function to slow responses to favor successful no-go trials has been related to the caudate nucleus; Boelher et al., 2010), to the enhanced visual computing that occurs during inhibitory control (which engaged left superior occipital regions; Leroux et al., 2006) and to emotional conflict processing (left amygdala; Etkin et al., 2006).

All together, these data appear to indicate that, while light drinkers disclosed an "executive-based" neural response to errors (e.g. planning future actions through RI and motor response selection; “Next time I should not click on W"), heavy drinkers are more engaged in a "visually-driven emotional strategy" (e.g. planning future motor action by enhancing visual processes of the salient stimuli, decreasing hit rate to Go trials in order to avoid the negative emotion triggered by a failed response; such as "Oh no, it was not the letter M"). Overall, at the structural level, brain atrophy associated with chronic alcohol consumption is a common finding, with enlarged ventricles and sulci as well as generalized loss of volume in cortical gray matter, 
white matter, cerebellum and subcortical structures (e.g., Pfefferbaum et al., 1992). Longitudinally, deformation-based morphometry confirmed tissue recovery (mainly in focal parts of the fronto-ponto-cerebellar circuit) in recovering alcoholics who maintain long-term sobriety (e.g., Cardenas et al., 2007). It is intriguing to wonder whether these brain abnormalities may have predated drug-taking, rendering individuals vulnerable for the development of dependence. Abnormalities in frontostriatal brain systems implicated in self-control in both stimulant-dependent individuals and their biological siblings who have no history of chronic drug abuse have been found and may indicate markers of neural vulnerability for pathological habits in drug addiction typically resulting in compulsive drug-taking behaviors when prefrontal control fails to regulate behavior (e.g., Ersche et al., 2012). In addition, the physiological correlates of the effects of alcohol on the brain have been examined with a range of techniques, with most suggesting that acute alcohol consumption results in numerous brain changes, including increases in cerebral blood flow (CBF) (e.g., Schuckit et al., 1988). CBF increases with alcohol were less prominent in individuals who required more drinks to experience alcohol-related effects (showing a low response -LR- to alcohol), this relationship indexing a robust marker of an enhanced risk for future alcohol problems (e.g., Tolentino et al., 2011). Also, at the functional level, the role of neural alterations in cognitive control mechanisms (reviewed by Luijten et al., 2014) as well as of error awareness (Garavan and Stout, 2005) in triggering addictions has become widely accepted. Tasks that are often used to measure inhibitory control are the go/no-go task and the stop signal reaction time task (SSRT), a test that measures the ability to stop a response that has already been initiated thanks to a warning cue (see Goldstein and Volkow, 2011 for a review). Consuming alcohol is known to impair inhibitory skills as well as error processing, as 
in go/no-go tasks (e.g., Easdon et al., 2005) than in SSRT (e.g., Li et al., 2009). Yet neural differences in the inhibitory circuitry observable before the initiation of heavy drinking may, however, predict the onset of substance abuse (Wetherill et al., 2013). Clearly, the present study did not allow us to determine whether neural differences observed with failed inhibitions were due to neural predispositions (i.e. present before the onset of alcohol drinking) and/or to alcohol consumption. However, by comparing healthy participants engaged in light vs. heavy social drinking habits, our study appears to indicate that, while the neural network necessary to achieve correct inhibitions is similar across participants, the neural network subtending commission errors is completely different in light vs. heavy drinkers. The "rationale-executive" neural response of light drinkers contrasted with the more "visual-perceptiveemotional" reaction of heavy drinkers. We suggest that these neural differences subtending error processing could index an "impaired insight" at the functional level that may lead patients to deny the severity of their illness, thereby contributing to the transition to addiction as well as to addiction persistence (Goldstein et al., 2009). Future longitudinal fMRI studies (comparable to Wetherill and colleagues' study (2013)) should be envisaged to investigate whether young social drinkers displaying this pattern of neural activity to failed inhibitions are actually at a higher risk to develop long-term alcohol abuse. In this view, participants with low vs. high responsiveness to alcohol (LR vs. HR groups) should also be taken into account in further studies. Indeed, for instance, Schuckit and colleagues (2012) showed through a SSRT that, despite similar group task performance, LR group demonstrated relatively less, whereas the HR group demonstrated more, error- and inhibition- related BOLD activations. These data suggest a brain mechanism that may contribute to how a low 
responsiveness to alcohol might enhance the risk for future heavy drinking and alcohol dependence.

In conclusion, we are fully aware that our study suffers from some limitations. For instance, the present results have to be cautiously considered due to small sample size and further studies should involve larger samples in order to test for reproducibility of our data (Button et al., 2013). Besides including LR and HR participants, larger samples would also allow investigating for sex influence. Indeed, (1) men are consistently more than twice as likely as women to report chronic heavy drinking (e.g. Meyer et al.,2000); and (2) gender differences in regional brain activation to response inhibition have been highlighted in a fMRI study (Ray Li et al., 2006), suggesting that, during RI, men activated the motor circuitry while women appeared to involve visual association or habit learning. It could therefore be highly relevant to reproduce the current study with higher samples of females and males in order to investigate for possible sex differences. Another limitation refers to the fact that some authors prefer to use an extremely difficult situation of inhibitory control in a challenging stop task by using an algorithm that adjusts the task individually so that each subject only succeeds in half of all the stop trials, while failing in the other half (Rubia et al., 2003; 2005; 2007). This allows computation of contrasts between an equal number of correct and failed inhibitions in order to separate brain activation related to successful motor response inhibition and to inhibition failure or error detection (Rubia et al., 2003). In the present study, we used a simpler Go/No-go task (Criaud and Boulinguez, 2013), which by controlling task accuracy allows the same number of trials (correct or failed) between groups to be compared. Further studies should use more complex inhibitory tasks to investigate whether (i) this would affect the behavioral performances of social drinkers; and (ii) this would have a specific 
impact on the neural network devoted to correct and failed inhibitions. Also, the use of a more complex task could allow more errors to be triggered, thus allowing examination of the neural networks devoted to errors in different contexts. Indeed, in the present study, we reduced error to a unique condition, mainly due to the small ratio. However, while some studies reported no impact of an alcohol-related context on correct/failed inhibitions (Nederkoorn et al., 2009; Houben et al., 2012; Mainz et al., 2012; Petit et al., 2014), others were able to show higher commission error rates, as alcohol-related cues are supposed to grab attention and decrease inhibitory skills (Greeley et al., 1993; Cox et al., 1999; Herrmann et al., 2001; Noël et al., 2005; Bartholow et al., 2007; 2010; Stacy and Wiers, 2010). Moreover, in the present study, behavioral data showed that a higher rate of commission errors could be seen in NC compared to AC and NAC in all of the participants, while it could be expected that by grabbing attention, contextual no-go trials may be more difficult to inhibit. A possible explanation could be that, due to a better visual contrast of the letters displayed on the black screen, NC context triggered faster RTs to Go trials and then a higher rate of commission errors (e.g., Dhar et al., 2011). We therefore suggest that further studies should use other forms of experimental designs, by adapting the current go/no-go task (no NC context? individual feedback to speed responses to Go trials?) or by using a SSRT (e.g., Verbruggen and Logan, 2008). Indeed, besides classical go and go-go stimuli, using SSRT would allow by including stop warning signals to investigate for proactive control strategies (that relies upon the anticipation and prevention of interference before it occurs) as well as for reactive control strategies (that relies upon the detection and resolution of interference after its onset). As both can be differently affected in pathological populations (Aron, 2011; Verbruggen et al., 2012; Pani et al., 2013), such a design may be particularly well-suited to investigate whether the neural 
networks devoted to correct and failed inhibitions may be modulated by contexts that may or may not be related to alcohol.

\section{Conclusions}

The main finding of the present study is that, even though light and heavy drinkers exhibited a similar level of performance in a Go/No-go task, they displayed involvement of very different neural networks to failed inhibitions. Such neural differences in the absence of behavioral modification are typical findings when heavy social drinkers are compared to light ones (reviewed by Petit et al., 2014). According to a 'functional compensation view', decreases or absences in activation reflect deficits in brain function, and the concomitant increases in activation reflect 'attempted' or 'successful' compensation for these deficits (Pfefferbaum et al., 2001). Clearly, it remains unclear whether these different activations reflect the recruitment of different regions and processes indexing different strategies (assuming that regional process-specificity does not change with alcohol consumption), and/or alterations in the processes mediated by the recruited regions (as a result of neural plasticity and regional changes in process-specificity due to alcohol consumption). However, as clear previous fMRI data indicate that (1) altered inhibitory mechanisms may predict the future onset of substance abuse (Wetherill et al., 2013), and (2) impaired insight has a key-role in drug abuse development and persistence, the data obtained in the present study suggests that the different networks subtending inhibitory errors in light and heavy drinkers may be considered as vulnerability factors that may subtend the transition from a controlled heavy consumption behavior to a state of dependence. Further longitudinal studies designed to test this hypothesis are warranted. 


\section{Acknowledgments}

Salvatore Campanella is Research Associate at the Fund of Scientific Research (FRSFNRS, Belgium). Mathieu Bourguignon benefits of a research grant from the FRIA (FRS-FNRS, Belgium). Xavier De Tiège is "Postdoctorate Clinical Master Specialist" at the Fund of Scientific Research (FRS-FNRS, Belgium).

\section{Compliance with Ethical Standards:}

\section{Disclosure: Funding/Conflict of interest}

This study was financially supported by the Fund of Scientific Research (Research Grant J.0009.13, FRS-FNRS, Belgium). The authors have no competing financial interest, potential conflict of interest, or financial relationship with commercial entities to report. They are funded by the Belgian Fund for Scientific Research (F.N.R.S., Belgium), but this fund did not exert any editorial direction or censorship on any part of this article.

\section{Ethical approval}

All procedures performed in studies involving human participants were in accordance with the ethical standards of the institutional and/or national research committee and with the 1964 Helsinki declaration and its later amendments or comparable ethical standards.

Informed consent was obtained from all individual participants included in the study. 


\section{References}

Albert, J., Lopez-Martın, S., Carretié, L. (2010). Emotional context modulates response inhibition: neural and behavioral data. Neuroimage, 49, 914-921.

Aron, A., Robbins, T., Poldrack, R. (2004). Inhibition and the right inferior frontal cortex. Trends in Cognitive Sciences, 8: 170-177.

Aron A. From reactive to proactive and selective control: developing a richer model for stopping inappropriate responses. Biol Psychiatry 2011, 69: 55-68.

Babor, T., Campbell, R., Room, R., Saunders, J. (1994). Lexicon of Alcohol and Drug Terms. World Health Organization, Geneva.

Babor, T., Higgins-Biddle, J. (2001). Brief intervention for hazardous and harmful drinking: a manual for use in primary care. World Health Organization, Department of Blood Safety and Clinical Technology.

Bari, A., Robbins, T. (2013). Inhibition and impulsivity: behavioral and neural basis of response control. Progress in Neurobiology, 108, 44-79.

Bartholow, B., Henry, E., Lust, S. (2007). Effects of alcohol sensitivity on P3 event-related potential reactivity to alcohol cues. Psychology of Addictive Behavior 21: $555-563$.

Bartholow, B., Lust, S., Tragesser, S. (2010.) Specificity of P3 event-related potential reactivity to alcohol cues in individuals low in alcohol sensitivity. Psychology of Addictive Behavior, 24, 220-228.

Beck, A.T., Steer, R.A. (1987). Beck Depression Inventory Manual. 1st ed. San Antonio: Psychological Corporation.

Behrmann, M., Geng, J. J., Shomstein, S. (2004). Parietal cortex and attention. Current Opinion in Neurobiology, 14(2), 212-217. 
Boehler, C. N., Appelbaum, L. G., Krebs, R. M., Hopf, J. M., Woldorff, M. G. (2010). Pinning down response inhibition in the brain - conjunction analyses of the stop-signal task. Neuroimage, 52(4), 1621-1632.

Boly, M., Coleman, M. R., Davis, M. H., Hampshire, A., Bor, D., Moonen, G., et al. (2007). When thoughts become action: an fMRI paradigm to study volitional brain activity in non-communicative brain injured patients. Neuroimage, 36(3), 979992.

Bonomo, Y.A., Bowes, G., Coffey, C., Carlin, J.B., Patton, G.C. (2004). Teenage drinking and the onset of alcohol dependence: a cohort study over seven years. Addiction 99: 1520-1528.

Botvinick, M. M., Cohen, J. D., Carter, C. S. (2004). Conflict monitoring and anterior cingulate cortex: an update. Trends in Cognitive Sciences, 8(12), 539-546.

Bradley, K. A., Bush, K. R., Epler, A. J., Dobie, D. J., Davis et al. (2003). Two brief alcohol-screening tests From the Alcohol Use Disorders Identification Test (AUDIT): validation in a female Veterans Affairs patient population. Archives of Internal Medicine, 163(7), 821-829.

Braver, T. S., Barch, D. M., Gray, J. R., Molfese, D. L., Snyder, A. (2001). Anterior cingulate cortex and response conflict: effects of frequency, inhibition and errors. Cerebral Cortex, 11(9), 825-836.

Bush, K., Kivlahan, D. R., McDonell, M. B., Fihn, S. D., Bradley, K. A. (1998). The AUDIT alcohol consumption questions (AUDIT-C): an effective brief screening test for problem drinking. Archives of internal medicine, 158(16), 17891795.Button, K. S., Ioannidis, J. P., Mokrysz, C., Nosek, B. A., Flint, J., et al. (2013). Power failure: why small sample size undermines the reliability of neuroscience. Nature Reviews Neuroscience, 14(5), 365-376. 
Cai, W., Leung, H. C. (2011). Rule-guided executive control of response inhibition: functional topography of the inferior frontal cortex. PloS one, 6(6), e20840.

Campanella, S., Peigneux, P., Petit, G., Lallemand, F., Saeremans, M., Noël, X. et al. (2013). Increased cortical activity in binge drinkers during working memory task: a preliminary assessment through a functional magnetic resonance imaging study. PloS one, 8(4), e62260.

Campbell, A.M.G., Evans, M., Thomson, J.L.G., Williams, M.J. (1971). Cerebral atrophy in young cannabis smokers. Lancet 298: 1219-1224.

Cardenas, V. A., Studholme, C., Gazdzinski, S., Durazzo, T. C., Meyerhoff, D. J. (2007). Deformation-based morphometry of brain changes in alcohol dependence and abstinence. Neuroimage, 34(3), 879-887.

Carretié, L., Hinojosa, J.A., Albert, J., Mercado, F. (2006). Neural response to sustained affective visual stimulation using an indirect task. Experimental Brain Research, 174: 630-637.

Chambers, C., Garavan, H., Bellgrove, M. (2009). Insights into the neural basis of response inhibition from cognitive and clinical neuroscience. Neuroscience and Biobehavioral Reviews, 33: 631-646.

Chassin, L., Pitts, S.C., Prost, J. (2002) Binge drinking trajectories from adolescence to emerging adulthood in a high-risk sample: predictors and substance abuse outcomes. Journal of Consulting and Clinical Psychology, 70(1):67-78.

Choudhury, S., Blakemore, S. J., Charman, T. (2006). Social cognitive development during adolescence. Social Cognitive and Affective Neuroscience, 1(3), 165-174. 
Cirilli, L., de Timary, P., Lefèvre, P., Missal, M. (2011). Individual differences in impulsivity predict anticipatory eye movements. PlosOne 10: e26699.

Cox, W.M., Yeates, G.N., Regan, C.M. (1999). Effects of alcohol cues on cognitive processing in heavy and light drinkers. Drug and Alcohol Dependence, 55: 85-89.

Crego, A., Holguín, S.R., Parada, M., Mota, N., Corral, M., Cadaveira, F. (2009). Binge drinking affects attentional and visual working memory processing in young university students. Alcoholism: Clinical Experimental Research, 33, 18701879.

Crego, A., Rodriguez-Holguín, S., Parada, M., Mota, N., Corral, M., Cadaveira, F. (2010) Reduced anterior prefrontal cortex activation in young binge drinkers during a visual working memory task. Drug and Alcohol Dependence, 109: $45-56$.

Crego, A., Cadaveira, F., Parada, M., Corral, M., Caamaño-Isorna, F., Rodriguez-Holguín, S. (2012) Increased amplitude of P3 event-related potential in young binge drinkers. Alcohol 46: 415-425.

Crews, F.T., Buckley, T., Dodd, P.R., Ende, G., Foley, H., Harper, C., et al. (2005). Alcoholic Neurobiology: Changes in Dependence and Recovery. Alcoholism: Clinical Experimental Research, 29: 1504-1513.

Criaud, M., \& Boulinguez, P. (2013). Have we been asking the right questions when assessing response inhibition in go/no-go tasks with fMRI? A meta-analysis and critical review. Neuroscience \& biobehavioral reviews, 37(1), 11-23.

De Zubicaray, G. I., Andrew, C., Zelaya, F. O., Williams, S. C. R., \& Dumanoir, C. (2000). Motor response suppression and the prepotent tendency to respond: a parametric fMRI study. Neuropsychologia, 38(9), 1280-1291. 
Dhar M, Wiersema JR, Pourtois G. Cascade of Neural Events Leading from Error Commission to Subsequent Awareness Revealed Using EEG Source Imaging. PLoS ONE 2011, 6(5): e19578.

Easdon, C., Izenberg, A., Armilio, M L., Yu, H, Alain, C (2005). Alcohol consumption impairs stimulus-and error-related processing during a Go/No-Go Task. Cognitive Brain Research, 25(3), 873-883.

Ehlers CL, Phillips E, Finnerman G, Gilder D, Lau P, and Criado J. (2007) P3 components and adolescent binge drinking in Southwest California Indians. Neurotoxicol Teratol, 29: 153-163.

Ernst, M., Bolla, K., Mouratidis, M., Contoreggi, C., Matochik, J. A., Kurian, et al. (2002). Decision-making in a risk-taking task: a PET study. Neuropsychopharmacology 26, 682-691.

Ersche, KD, Jones, PS, Williams, GB, Turton, AJ, Robbins, TW, Bullmore, ET (2012). Abnormal brain structure implicated in stimulant drug addiction. Science, 335(6068), 601-604.

Etkin, A., Egner, T., Peraza, D. M., Kandel, E. R., Hirsch, J. (2006). Resolving emotional conflict: a role for the rostral anterior cingulate cortex in modulating activity in the amygdala. Neuron, 51(6), 871-882.

Field M., Kiernan A., Eastwood B., Child R. Rapid approach responses to alcohol cues in heavy drinkers. J Behav Ther Exp Psychiatry 2008;39:209-218.

Friston KJ, Buechel C, Fink GR, Morris J, Rolls E, Dolan RJ. (1997). Psychophysiological and modulatory interactions in neuroimaging. Neuroimage, 6(3), 218-229. 
Friston, K. J., Fletcher, P., Josephs, O., Holmes, A., Rugg, M. D., \& Turner,

R. (1998). Event-related fMRI: characterizing differential responses. NeuroImage, 7(1), 30-40.

Friston K (2003). Introduction: experimental design and statistical parametric mapping. In: Frackowiak R, Friston K, Frith C, Dolan R, Price C, Zeki S, Ashburner J, Penny W, editors. Human Brain Function. London: Academic Press.

Friston, K. J., Stephan, K. E., Lund, T. E., Morcom, A., \& Kiebel, S. (2005). Mixed-effects and fMRI studies. NeuroImage, 24(1), 244-252.

Garavan, H., Ross, T. J., Kaufman, J., Stein, E. A. (2003). A midline dissociation between error-processing and response-conflict monitoring. Neuroimage, 20(2), 1132-1139.

Garavan, H., \& Stout, J. C. (2005). Neurocognitive insights into substance abuse. Trends in cognitive sciences, 9(4), 195-201.

Gitelman, D. R., Penny, W. D., Ashburner, J., Friston, K. J. (2003). Modeling regional and psychophysiologic interactions in fMRI: the importance of hemodynamic deconvolution. Neuroimage, 19(1), 200-207.

Greeley JD, Swift W, Prescott J, Heather N (1993) Reactivity to alcoholrelated cues in heavy and light drinkers. J Stud Alcohol 54: 359-368.

Goldstein, R. Z., Volkow, N. D., Wang, G. J., Fowler, J. S., Rajaram, S. (2001). Addiction changes orbitofrontal gyrus function: involvement in response inhibition. Neuroreport, 12(11), 2595.

Goldstein, R. Z., Bechara, A., Garavan, H., Childress, A. R., Paulus, M. P., Volkow, N. D. (2009). The neurocircuitry of impaired insight in drug addiction. Trends in cognitive sciences, 13(9), 372-380. 
Goldstein, R. Z., Volkow, N. D. (2011). Dysfunction of the prefrontal cortex in addiction: neuroimaging findings and clinical implications. Nature Reviews Neuroscience, 12(11), 652-669.

Hall GH (1970) Effects of nicotine and tobacco smoke on the electrical activity of the cerebral cortex and olfactory bulb. Brit J Pharmacol 38: 271-286.

Henges, A. L., Marczinski, C. A. (2012). Impulsivity and alcohol consumption in young social drinkers. Addictive behaviors, 37(2), 217-220.

Herrmann MJ, Weijers HG, Wiesbeck GA, Böning J, Fallgatter AJ (2001) Alcohol cue-reactivity in heavy and light social drinkers as revealed by event-related potentials. Alcohol Alcohol 36: 588-593.

Hermens DF, Lagopoulos J, Tobias-Webb J, De Regt T, Dore G, et al (2013). Pathways to alcohol-induced brain impairment in young people: A review. Cortex 49(1): 3-17.

Holmes, A., Poline, J. B., \& Friston, K. (1997). Characterizing brain images with the general linear model. In R. Frackowiak, K. Friston, C. Frith, R. Dolan \& J. C. Mazziotta (Eds.), Human brain function (pp. 59-84). farde London: Academic Press.

Houben, K., Havermans, R. C., Nederkoorn, C., Jansen, A. (2012). Beer à No-Go: Learning to stop responding to alcohol cues reduces alcohol intake via reduced affective associations rather than increased response inhibition. Addiction, 107(7), 1280-1287.

Jacques, P. L. S., Dolcos, F., \& Cabeza, R. (2009). Effects of aging on functional connectivity of the amygdala for subsequent memory of negative pictures a network analysis of functional magnetic resonance imaging data. Psychological science, 20(1), 74-84. 
Jonker T, Seli P, Cheyne J, Smilek D. Performance reactivity in a continuousperformance task: Implications for understanding post-error behavior. Conscious Cogn 2013, 22: 1468--1476.

Leroux, G., Joliot, M., Dubal, S., Mazoyer, B., Tzourio-Mazoyer, N., Houdé, O. (2006). Cognitive inhibition of number/length interference in a Piaget-like task in young adults: Evidence from ERPs and fMRI. Human brain mapping, 27(6), 498-509.

Li, C. S., Luo, X., Yan, P., Bergquist, K., Sinha, R. Altered impulse control in alcohol dependence: neural measures of stop signal performance. Alcohol. Clin. Exp. Res. 33, 740-750 (2009).

Liebowitz, M. R. (1987). Social phobia (pp. 141-173). Karger Publishers.

Luijten, M., Machielsen, M. W., Veltman, D. J., Hester, R., Haan, L. D., Franken, I. H. (2014). Systematic review of ERP and fMRI studies investigating inhibitory control and error processing in people with substance dependence and behavioural addictions.

López-Caneda E, Cadaveira F, Crego A, Gómez-Suárez A, Corral M, et al. (2012) Hyperactivation of right inferior frontal cortex in young binge drinkers during response inhibition: a follow-up study. Addiction 107: 1796-1808.

Mainz, V., Drüke, B., Boeker, M., Kessel, R., Gauggel, S., Forkmann, T. Influence of cue exposure on inhibitory control and brain activation in patients with alcohol dependence. Front Hum Neurosci, 2012;6: 1-13.

Mahmood, O. M., Goldenberg, D., Thayer, R., Migliorini, R., Simmons, A. N., Tapert, S. F. (2013). Adolescents' fMRI activation to a response inhibition task predicts future substance use. Addictive behaviors, 38(1), 1435-1441. 
Maurage, P., Pesenti, M., Philippot, P., Joassin, F., Campanella, S. (2009) Latent deleterious effects of binge drinking over a short period of time revealed only by electrophysiological measures. J Psychiatry Neurosci, 34, 111-118.

Maurage P, Joassin F, Speth A, Modave J, Philippot P, et al. (2012) Cerebral effects of binge drinking: respective influences of global alcohol intake and consumption pattern. Clin Neurophysiol 123: 892-901.

Massat, I., Slama, H., Kavec, M., Linotte, S., Mary, A., Baleriaux, D., et al. (2012). Working memory-related functional brain patterns in never medicated children with ADHD. PloS one, 7(11), e49392.

McGue M (1994) Genes, environment, and the etiology of alcoholism. In: Zucker R, Boyd G, Howard J, editors. The Development of Alcohol Problems: Exploring the Biopsychosocial Matrix of Risk (NIAAA Research Monograph No. 26). US Government Printing Office; Washington, DC: pp 1-40.

McKenzie M, Jorm AF, Romaniuk H, Olsson CA, Patton, GC (2011): Association of adolescent symptoms of depression and anxiety with alcohol use disorders in young adulthood: findings from the Victorian Adolescent Health Cohort Study. Med J Aust 195: 27-30.

Menon, V., Adleman, N. E., White, C. D., Glover, G. H., Reiss, A. L. (2001). Error-related brain activation during a Go/NoGo response inhibition task. Human brain mapping, 12(3), 131-143.

Meyer, C., Rumpf, H.J., Hapke, U., Dilling, H., John, U. (2000).Prevalence of alcohol consumption, abuse and dependence in a country with high per capita consumption: findings from the German TACOS study. Transitions in Alcohol Consumption and Smoking. Social Psychiatry and Psychiatric Epidemiology 35 (12),539-547. 
Murphy, E. R., Foss-Feig, J., Kenworthy, L., Gaillard, W. D., \& Vaidya, C. J. (2012). Atypical functional connectivity of the amygdala in childhood autism spectrum disorders during spontaneous attention to eye-gaze. Autism research and treatment, 2012.

Nederkoorn, C., Baltus, M., Guerrieri, R., Wiers, R. W. (2009). Heavy drinking is associated with deficient response inhibition in women but not in men. Pharmacology Biochemistry and Behavior, 93(3), 331-336.

Nee, D. E., Kastner, S., Brown, J. W. (2011). Functional heterogeneity of conflict, error, task-switching, and unexpectedness effects within medial prefrontal cortex. Neuroimage, 54(1), 528-540.

Nicolas JM, Estruch R, Salamero M, Orteu N, Fernandez-Sola J, et al (1997) Brain impairment in well-nourished chronic alcoholics is related to ethanol intake. Ann Neurol 41: 590-598.

Noël, X., Van der Linden, M., d'Acremont, M., Colmant, M., Hanak, C., et al. (2005). Cognitive biases toward alcohol-related words and executive deficits in polysubstance abusers with alcoholism. Addiction, 100(9), 1302-1309.

Norberg, MN, Oliver, J, Alperstein, DM, Zvolensky, MJ, Norton, AR (2011). Adverse consequences of student drinking: The role of sex, social anxiety, drinking motives. Addict Behav 36: 821-828.

Norman, A. L., Pulido, C., Squeglia, L. M., Spadoni, A. D., Paulus, M. P., Tapert, S. F. (2011). Neural activation during inhibition predicts initiation of substance use in adolescence. Drug and alcohol dependence, 119(3), 216-223.

Oldfield, R.C. (1971). The assessment and analysis of handedness: the Edinburgh Inventory. Neuropsychologia 9: 97-113. 
Pani P, Menghini D, Napolitano C, et al. Proactive and reactive control of movement are differently affected in Attention Deficit Hyperactivity Disorder children. Res Dev Disabil 2013, 34: 3104-3111.

Peigneux, P., Orban, P., Balteau, E., Degueldre, C., Luxen, A., Laureys, S., et al. (2006). Offline persistence of memory-related cerebral activity during active wakefulness. PLoS Biol. 4, e100.

Penny, W., Holmes, A. (2003). Random-effect analysis. In: Frackowiak R, Friston K, Frith C, Dolan R, Price C, Zeki S, Ashburner J, Penny W, editors. Human Brain Function. London: Academic Press.

Petit, G., Kornreich, C., Noël, X., Verbanck, P., Campanella, S. (2012). Alcohol-Related Context Modulates Performance of Social Drinkers in a Visual Go/No-Go Task: a Preliminary Assessment of Event-Related Potentials. PlosOne, 7(5), e37466.

Petit, G., Cimochowska, A., Kornreich, C., Hanak, C., Verbanck, P., Campanella, S. (2014). Neurophysiological correlates of response inhibition predict relapse in detoxified alcoholic patients: some preliminary evidence from event-related potentials. Neuropsychiatric Disease and Treatment, 10, 1025-1037.

Petit, G., Maurage, P., Kornreich, C., Verbanck, P., Campanella, S. (2014). Binge drinking in adolescents: a review of neurophysiological and neuroimaging research. Alcohol and alcoholism, 49(2), 198-206.

Pfefferbaum, A., Lim, K.O., Zipursky, R.B., Mathalon, D.H., Rosenbloom, et al. (1992). Brain gray and white matter volume loss accelerates with aging in chronic alcoholics: a quantitative MRI study. Alcohol Clin Exp Res 16 (6), 1078-1089. 
Pfefferbaum A, Desmond JE, Galloway C, Menon V, Glover GH, et al. (2001) Reorganization of frontal systems used by alcoholics for spatial working memory: an fMRI study. NeuroImage 14:7-20.

Picard, N., Strick, P. L. (1996). Motor areas of the medial wall: a review of their location and functional activation. Cerebral cortex, 6(3), 342-353.

Ray Li C, Huang C, Constable T, Sinha R. Gender differences in the neural correlates of response inhibition during a stop signal task. NeuroImage 2006, 32 : 1918-1929.

Ridderinkhof, K.R., de Vlugt, Y., Bramlage, A., Spaan, M., Elton, M., et al. (2002). Alcohol consumption impairs detection of performance errors in mediofrontal cortex. Science 298: 2209-2211.

Robinson, J. (2013). Edinburgh Handedness Inventory. In Encyclopedia of Autism Spectrum Disorders (pp. 1051-1054). Springer New York.

Rogers, R. D., Robbins, T. W. (2001). Investigating the neurocognitive deficits associated with chronic drug misuse. Current opinion in neurobiology, 11(2), 250-257.

Rubia, K., Smith, A. B., Brammer, M. J., Taylor, E. (2003). Right inferior prefrontal cortex mediates response inhibition while mesial prefrontal cortex is responsible for error detection. Neuroimage, 20(1), 351-358.

Rubia, K., Smith, A. B., Brammer, M. J., Toone, B., Taylor, E. (2005). Abnormal brain activation during inhibition and error detection in medication-naive adolescents with ADHD. American Journal of Psychiatry, 162(6), 1067-1075.

Rubia, K., Smith, A. B., Taylor, E., \& Brammer, M. (2007). Linear age-correlated functional development of right inferior fronto-striato-cerebellar 
networks during response inhibition and anterior cingulate during error-related processes. Human brain mapping, 28(11), 1163-1177.

Saunders JB, Aasland OG, Babor TF, de la Fuente JR, Grant M (1993) Development of the Alcohol Use Disorders Identification Test (AUDIT): WHO Collaborative Project on Early Detection of Persons with Harmful Alcohol Consumption--II. Addiction 88: 791-804.

Schuckit, MA., Tapert, S, Matthews, SC, Paulus, MP, Tolentino, NJ, et al. (2012). fMRI differences between subjects with low and high responses to alcohol during a stop signal task. Alcoholism: Clinical and Experimental Research, 36(1), 130-140.

Schuckit MA, Gold EO. A simultaneous evaluation of multiple markers of ethanol/placebo challenges in sons of alcoholics and controls. Arch Gen Psychiatry. $1988 ; 45: 211-216$.

Schweinsburg, A. D., Paulus, M. P., Barlett, V. C., Killeen, L. A., Caldwell, L. C., Pulido, C., et al. (2004). An FMRI study of response inhibition in youths with a family history of alcoholism. Annals of the New York Academy of Sciences, 1021(1), 391-394.

Schweinsburg AD, McQueeny T, Nagel BJ, Eyler LT, Tapert SF (2010) A preliminary study of functional magnetic resonance imaging response during verbal encoding among adolescent binge drinkers. Alcohol 44: 111-7.

Schweinsburg, A.D., Schweinsburg, B.C., Nagel, B.J., Eyler, L.T., Tapert, S.F. (2011) Neural correlates of verbal learning in adolescent alcohol and marijuana users. Addiction 106: 564-573.

Schilbach, L., Hoffstaedter, F., Müller, V., Cieslik, E. C., Goya-Maldonado, R., Trost, S., et al. (2016). Transdiagnostic commonalities and differences in resting 
state functional connectivity of the default mode network in schizophrenia and major depression. NeuroImage: Clinical, 10, 326-335.

Smith, LA, Foxcroft, DR (2009). The effect of alcohol advertising, marketing and portrayal on drinking behaviour in young people: systematic review of prospective cohort studies. BMC Public Health 9: 51.

Smith, J. L., Mattick, R. P. (2013). Evidence of deficits in behavioural inhibition and performance monitoring in young female heavy drinkers. Drug and alcohol dependence, 133(2), 398-404.

Spielberger CD (1983) Manual for the State-Trait Anxiety Inventory (STAI). Consulting Psychologists Press, Palo Alto, CA.

Squeglia, LM, Schweinsburg, AD, Pulido, C, Tapert, SF (2011) Adolescent binge drinking linked to abnormal spatial working memory brain activation: differential gender effects. Alcohol Clin Exp Res 35: 1831-1841.

Squeglia LM, Pulido C, Wetherill RR, Jacobus J, Brown GG, and Tapert SF. (2012) Brain response to working memory over three years of adolescence: influence of initiating heavy drinking. J Stud Alcohol Drugs 73(5): 749-760.

Stacy AW, Wiers RW (2010) Implicit cognition and addiction: a tool for explaining paradoxical behavior. Annu Rev Clin Psychol 6: 551-575.

Stevens, A. A., Skudlarski, P., Gatenby, J. C., Gore, J. C. (2000). Eventrelated fMRI of auditory and visual oddball tasks. Magnetic resonance imaging, 18(5), 495-502.

Strange, B. A., Hurlemann, R., Duggins, A., Heinze, H. J., Dolan, R. J. (2005). Dissociating intentional learning from relative novelty responses in the medial temporal lobe. Neuroimage, 25(1), 51-62. 
Swick, D., Turken, U. (2002). Dissociation between conflict detection and error monitoring in the human anterior cingulate cortex. Proceedings of the National Academy of Sciences, 99(25), 16354-16359.

Swick, D., Ashley, V., Turken, U. (2008). Left inferior frontal gyrus is critical for response inhibition. BMC neuroscience, $9(1), 1$.

Taylor, K. S., Seminowicz, D. A., Davis, K. D. (2009). Two systems of resting state connectivity between the insula and cingulate cortex. Human brain mapping, 30(9), 2731-2745.

Tolentino, NJ, Wierenga, CE, Hall, S, Tapert, SF, Paulus, MP, et al. (2011). Alcohol effects on cerebral blood flow in subjects with low and high responses to alcohol. Alcoholism: Clinical and Experimental Research, 35(6), 1034-1040.

Verbruggen, F., Logan, G. D. (2008). Response inhibition in the stop-signal paradigm. Trends in cognitive sciences, 12(11), 418-424.

Verbruggen F, Logan G. Automaticity of cognitive control: Goal priming in response-inhibition paradigms. J Exp Psychol 2009, 35(5): 1381-1388.

Verbruggen F, Adams R, Chambers C. Proactive motor control reduces monetary risk taking in gambling. Psychol Sci 2012, 23: 805-815.

Viner RM, Taylor B. (2007) Adult outcomes of binge drinking in adolescence: findings from a UK national birth cohort. J Epidemiol Community Health 61(10):902-907.

Vocat, R., Pourtois, G., Vuilleumier, P. (2008). Unavoidable errors: a spatiotemporal analysis of time-course and neural sources of evoked potentials associated with error processing in a speeded task. Neuropsychologia, 46(10), 2545-2555. 
Volkow, N. D., Fowler, J. S., Wang, G. J., Swanson, J. M. (2004). Dopamine in drug abuse and addiction: results from imaging studies and treatment implications. Molecular psychiatry, 9(6), 557-569.

Watanabe, J., Sugiura, M., Sato, K., Sato, Y., Maeda, Y., Matsue, Y., et al. (2002). The human prefrontal and parietal association cortices are involved in NO-GO performances: an event-related fMRI study. Neuroimage, 17(3), 1207-1216.

Wetherill, R. R., Squeglia, L. M., Yang, T. T., Tapert, S. F. (2013). A longitudinal examination of adolescent response inhibition: neural differences before and after the initiation of heavy drinking. Psychopharmacology, 230(4), 663-671.

Whiteside S.P., Lynam D.R. Understanding the role of impulsivity and externalizing psychopathology in alcohol abuse: application of the UPPS impulsive behavior scale. Exp Clin Psychopharmacol 2003;11:210-217.

Worsley KJ (1996) A unified statistical approach for determining significant signals in images of cerebral activation. Hum Brain Mapp 4: 58-73.

Xiao, L., Bechara, A., Gong, Q., Huang, X., Li, X., Xue, G., et al. (2013). Abnormal affective decision making revealed in adolescent binge drinkers using a functional magnetic resonance imaging study. Psychology of Addictive Behaviors, 27(2), 443. 


\section{Figure Captions}

Figure 1 - Go/No-Go task. Participants were confronted with 2 sessions of three blocks of 133 stimuli, divided in 93 Go trials (letter M), and 40 No-Go trials (letter W). The letters were superimposed on a long-lasting black background (No Context; NC); a non-alcohol-related background picture (NAC), and an alcohol-related background picture (AC).

Figure 2 - Through a full-factorial analysis, sagittal views with specific activations for the whole sample $(\mathrm{N}=36)$ were disclosed for each separate context ( $\mathrm{NC}, \mathrm{AC}, \mathrm{NAC})$. Brain areas activated for both groups across all contexts (null conjunction analysis) were also displayed ( $\mathrm{p}<.05$ corrected; for all $\mathrm{x}, \mathrm{y}, \mathrm{z}$ coordinates details, see Table 3 ).

Figure 3 - Sagittal and coronal views of bBrain areas activated in response to failed inhibitory trials in the whole sample $(\mathrm{N}=36$; One Sample t-test) were displayed. Group differences in brain activations to errors (Light vs. Heavy; Heavy vs. Light) were highlighted thanks to two-sample t-tests $(\mathrm{p}<.05$ corrected; for all $\mathrm{x}, \mathrm{y}, \mathrm{z}$ coordinates details, see Table 4). 


\title{
Neural correlates of correct and failed response inhibition in heavy versus light social drinkers: an fMRI study during a Go/No-go task by healthy participants
}

\author{
Salvatore CAMPANELLA ${ }^{1}$, Julie ABSIL $^{2}$, Carina CARBIA SINDE ${ }^{3}$, Elisa \\ SCHRODER $^{1}$, Philippe PEIGNEUX ${ }^{4}$, Mathieu BOURGUIGNON ${ }^{5,6}$, Mathieu \\ PETIAU $^{7}$, Thierry METENS ${ }^{2}$, Mustapha NOUALI ${ }^{2}$, Serge GOLDMAN ${ }^{5}$, Guy \\ $\mathrm{CHERON}^{7}$, Paul VERBANCK ${ }^{1}$, Xavier DE TIEGE $^{5}$ \\ ${ }^{1}$ Laboratoire de Psychologie Médicale et d'Addiction, ULB Neuroscience Institute (UNI), Université \\ Libre de Bruxelles (ULB), Belgium \\ ${ }^{2}$ Department of Radiology, ULB-Hôpital Erasme, Université Libre de Bruxelles (ULB), Brussels, \\ Belgium \\ ${ }^{3}$ Department of Clinical Psychology and Psychobiology, University of Santiago de Compostela, \\ Galicia, Spain \\ ${ }^{4}$ Neuropsychology and Functional Neuroimaging Research Unit (UR2NF) at Centre de Recherches en \\ Cognition et Neurosciences (CRCN), ULB Neuroscience Institute (UNI), Université Libre de Bruxelles \\ (ULB), Brussels, Belgium \\ ${ }^{5}$ Laboratoire de Cartographie fonctionnelle du Cerveau, ULB Neuroscience Institute (UNI), Université \\ Libre de Bruxelles (ULB), Brussels, Belgium \\ ${ }^{6}$ BCBL, Basque Center on Cognition, Brain and Language, San Sebastian, Spain \\ ${ }^{7}$ Laboratory of Neurophysiology and Movement Biomechanics, ULB Neuroscience Institute (UNI), \\ Université Libre de Bruxelles (ULB), Brussels, Belgium
}

Abbreviated form of the title:

Number of words of the abstract: 250

Number of words of the text: 7468

Number of tables: 4

Number of figures: 3

All correspondence should be sent to: Salvatore Campanella, $\mathrm{PhD}$, Research Associate, The Belgian Fund for Scientific Research (F.N.R.S.), CHU Brugmann, Psychiatry Secretary 4, Place Vangehuchten - B-1020 Brussels, Belgium Tel: +32 24773465 - Email: salvatore.campanella@chu-brugmann.be or salvatore.campanella@ulb.ac.be 


\section{Abstract}

The ability to suppress responses that are inappropriate, as well as the mechanisms monitoring the accuracy of actions in order to compensate for errors, is central to human behavior. Neural alterations that prevent stopping an inaccurate response, combined with a decreased ability of error monitoring, are considered to be prominent features of alcohol abuse. Moreover, (i) alterations of these processes have been reported in heavy social drinkers (i.e. young healthy individuals who do not yet exhibit a state of alcohol dependence); and (ii) through longitudinal studies, these alterations have been shown to underlie subsequent disinhibition that may lead to future alcohol use disorders. In the present functional magnetic resonance imaging study, using a contextual Go/No-go task, we investigated whether different neural networks subtended correct inhibitions and monitoring mechanisms of failed inhibitory trials in light versus heavy social drinkers. We show that, although successful inhibition did not lead to significant changes, neural networks involved in error monitoring are different in light versus heavy drinkers. Thus, while light drinkers exhibited activations in their right inferior frontal, right middle cingulate and left superior temporal areas; heavy drinkers exhibited activations in their right cerebellum, left caudate nucleus, left superior occipital region, and left amygdala. These data are functionally interpreted as reflecting a "visually-driven emotional strategy" vs. an "executive-based" neural response to errors in heavy and light drinkers, respectively. Such a difference is interpreted as a key-factor that may subtend the transition from a controlled social heavy consumption to a state of clinical alcohol dependence.

Keywords: Social Drinking; Alcohol; Functional magnetic resonance imaging; Go/No-go task; Cognitive control; Error awareness 


\section{Introduction}

Drug addiction is clearly linked with several deficient cognitive processes indexed by abnormal neural functioning (reviewed by Rogers and Robbins, 2001). It is well established that alcohol neurotoxicity from chronic alcohol dependence results in deleterious effects on the central nervous system, such as brain atrophy or dysfunction. This is thought to be mainly due to specific neurodegenerative mechanisms, inducing neuronal loss as well as brain structural and functional alterations (Crews et al., 2005). Moreover, these brain impairments correlate with the lifetime dose of ethanol consumed (Nicolas et al., 1997). Aside from these clear-cut effects induced by long-term heavy consumption, neuroimaging data also suggest that even minor cognitive restrictions can represent biological predictors of future alcohol abuse. There is indeed evidence suggesting that baseline decreased activity, or higher neural resources needed to achieve some specific cognitive functions, can predict substance use disorder in adolescence (Goldstein et al., 2001). For instance, by functional magnetic resonance imaging (fMRI) during a Go/No-go task it was shown youths with a family history of alcoholism displayed less frontal activity during response inhibition than did controls. This suggests that this altered neural activity may underlie subsequent disinhibition, potentially leading to future alcohol use disorders (Schweinsburg et al., 2004). Similarly, through longitudinal Go/No-go fMRI studies it was shown that future heavy drinkers exhibited less activation of the inhibitory circuitry (Norman et al., 2011; Wetherill et al., 2013), as well as less activity during performance monitoring (Smith and Mattick, 2013) before the onset of heavy drinking, thus suggesting that neural vulnerabilities may exist prior to the onset of alcohol abuse. These prior brain vulnerabilities are of the highest relevance, as the initiation of excessive alcohol consumption will, due to substance neurotoxicity, lead 
to additional alterations in brain functioning. All up, this may explain why anomalies displayed in heavy social drinkers can quickly mirror those observed in alcohol dependence (Petit et al., 2014 for a review), and why they are associated with an increased risk of subsequent long-lasting alcohol dependence (Chassin et al., 2002; Bonomo et al., 2004; Viner and Taylor, 2007). Heavy consumption is, however, not yet equivalent to dependence. The deficits are either less serious than those observed in alcoholism or, while they may be detectable by neuroimaging tools, they remain unexpressed at the behavioural level (reviewed by Hermens et al., 2013). It is therefore important to emphasize the need for more education in regard to the dangers of heavy social drinking, and for reconsideration of standard practices used to market alcohol to young people (Smith and Foxcroft, 2009), in order to avoid the potential of triggering the transition that leads from an excessive, but "controlled", consumption to a state of dependence.

While there have been several fMRI studies to date that have been able to link heavy social drinking with a decreased performance in various cognitive tasks (Squeglia et al., 2011, 2012; Xiao et al., 2013), most studies in this regard obtained evidence of neural differences without any behavioral modification or indexing compensation mechanisms (Schweinsburg et al., 2010; 2011; Campanella et al., 2013). This was also true when techniques other than fMRI, such as event-related potentials, were used (Ehlers et al., 2007; Crego et al., 2009, 2010, 2012; LopezCaneda et al., 2012; Maurage et al., 2009; 2012; Petit et al., 2012). The main aim of the present fMRI study was to compare the neural networks activated in heavy vs. light social drinkers (i.e. in healthy participants who do not exhibit an alcohol dependence) during a Go/No-go task when they perform equal successful and unsuccessful inhibitions. 
The ability to withhold inadequate responses (e.g., laughing during a funeral) is central to human behavior. Response inhibition (RI) is considered to be a key component of executive control, as it refers to the ability to suppress responses that are no longer required or contextually inappropriate, supporting flexible goal-directed behavior in ever-changing environments, and allowing individuals to recover from potentially harmful situations before it is too late (Verbruggen and Logan, 2009). However, when inhibition fails, registering the unwanted self-generated outcome is the first step to be able to adjust one's own actions (Vocat et al., 2008). In this view, error detection (ED) is among the highest evolved human self-monitoring functions (Rubia et al., 2003; Ridderinkhof et al., 2004). A vast set of experimental studies has been devoted to both processes, indicating that a complex neural circuit involving both cortical (such as the inferior frontal cortex (IFC) and the pre-supplementary motor area (pre-SMA)) and subcortical regions (e.g. basal ganglia structures) allow for the successful inhibition of a prepotent motor response (reviewed by Bari and Robbins, 2013), while the dorsal anterior cingulate cortex (dACC) plays a central role in signaling the occurrence of conflicts in information processing, thereby triggering compensatory adjustment mechanisms (reviewed by Botvinick et al., 2004).

Overall, on the one hand, neural alterations to RI prevent stopping of a prepotent response (e.g. drug consumption). On the other hand, a decreased ability of ED, also called "error awareness" (Garavan and Stout, 2005), which function is to lead to optimization of behavioral responses, appeared as a main feature subtending the continuation of the addictive behavior. Altogether, simultaneous deficits of RI and ED may trigger the onset and the persistence of alcohol abuse despite repeatedly negative consequences (reviewed by Volkow et al., 2004; Luijten et al., 2014). Moreover, while some studies reported no impact of alcohol-related context on 
correct/failed inhibitions (Nederkoorn et al., 2009; Houben et al., 2012; Mainz et al., 2012; Petit et al., 2014), others have shown higher commission error rates, as alcoholrelated cues are supposed to grab attention and decrease inhibitory skills (Greeley et al., 1993; Cox et al., 1999; Herrmann et al., 2001; Noël et al., 2005; Bartholow et al., 2007; 2010; Stacy and Wiers, 2010). With this in mind, three main questions will be investigated in the present study. Firstly, we aim to examine how context can modulate the inhibitory performance of light vs. heavy social drinkers. To achieve this aim, we used a variant of the Go/No-go task, in which Go and No-go trials were displayed on long-lasting background contexts (neutral (NC), alcohol-related (AC), non-alcohol-related (NAC)). Indeed, controlling drinking behavior within long-term affective situations is often required, and behavioral and neural reactions provoked by short-duration stimuli are clearly not as intense or complex as those generated by longer emotional contexts (Carretié et al., 2006; Albert et al., 2010). Such a "contextual Go/No-go task" has already been used in our laboratory with social drinkers during an ERP recording (Petit et al., 2012) In that study, behavioral results disclosed no main group effect, but a marginal significant interaction group $\mathrm{x}$ context $(p=0.082)$, as heavy drinkers had a similar amount of commission errors independent of contexts (between 20-22\%), while light drinkers exhibited fewer commission errors in AC than in NAC and NC (15\% vs. 18-19\%). Interestingly, when confronted with the same task, recently detoxified alcoholic patients disclosed more commission errors than matched controls, but independently of the context (mean of $22 \%$ vs. $11 \%$ ) (Petit et al., 2014). Given these contradictory results, we decided to investigate potential differences in neural networks involved when heavy and light social drinkers have to perform inhibition on alcohol or non-alcohol related contexts. Secondly, we expected that, independently of contexts, by controlling for some 
individual personality factors that are well-known to influence inhibitory skills (such as impulsivity for instance; Noël et al., 2005), heavy and light social drinkers would perform the task similarly (as in Wetherill et al., 2013). This would allow us to compare a same amount of successful trials between groups. We hypothesized that even in the absence of group behavioral differences; heavy drinkers would recruit a different neural network as compared to light drinkers to achieve successful inhibitions, as was found to be the case in a previous study of ours when both groups performed equally well in a short-term verbal memory N-back task (Campanella et al., 2013). Thirdly, keeping in mind what was said in regard to correct inhibitory trials, the same logic may be applied to failed trials, as we expected that, for the same amount of commission errors, light and heavy drinkers will disclose a different neural network to monitor their errors.

\section{Materials and Methods}

\section{Participants}

First of all, a general screening of 150 students from the Faculty of Psychology at the University of Brussels (Belgium) was conducted in order to ascertain patterns of alcohol consumption. For this purpose, students filled in a questionnaire assessing their alcohol-drug consumption behavior as well as personal data and psychological parameters. On the basis of these self-reported data, groups of participants were defined as detailed below. Exclusion criteria for participants included major medical issues, conditions relating to impairment of the central nervous system (including epilepsy and a prior history of brain injury), visual impairments, and past or current drug consumption (other than alcohol and tobacco use). Our main objective was to select two groups of participants who only displayed 
differences in terms of their alcohol-drinking pattern (see Table 1 for complete descriptive data). Since there was a high co-occurrence of excessive drinking and substance use, such as cannabis and tobacco (Hall, 1970; Campbell et al., 1971), subjects concurrently consuming cannabis (defined as at least once in the month prior to the study) were not included. Also, a similar number of participants with a family history of alcoholism (FHA) (McGue, 1994) were included in the final groups. The Alcohol Use Disorder Identification Test (AUDIT) was used to evaluate participants in regard to hazardous drinking, harmful drinking, or alcohol dependence (Saunders et al., 1993). AUDIT scores were used to include participants in light versus excessive social drinker groups. Participants were only classified as heavy drinkers if their score on the AUDIT was equal to or above the cut-off score of 8 , which is an indicator of hazardous drinking (Babor and Higgins-Biddle, 2001), while they were considered to be light drinkers if they scored a 7 or lower (Field et al., 2008). This classification was confirmed utilizing the AUDIT-C consumption subscore, which is defined by three items of the complete 10-items AUDIT instrument, and which can help identify people who are hazardous drinkers (Bush et al., 1998). The AUDIT-C is scored on a scale $0-12$. A score of 3 for women and 4 for men is considered optimal for identifying hazardous drinkers; the higher the score, the more likely drinking pattern affects participants' safety (Bradley et al., 2003). Participants were also asked to report the mean number of alcohol doses (one dose corresponding to 10 grams of pure ethanol) they consumed in a week during the last six months ("In the last six months, how many drinks do you consume in a week in general?"). Hazardous drinking, which can significantly impact public health despite the absence of any bona fide disorder in the individual users, is defined as a level of alcohol consumption likely to result in harm to the user or other individuals (Babor et al., 1994). 
In order to ensure that any potential difference in the fMRI data would be due to alcohol consumption and not to other variables, groups were balanced for righthandedness (assessed with the Edinburgh scale (Oldfield, 1971)), age, gender, and level of education (i.e. the number of years of education completed since starting primary school). Participants were also asked to fill out questionnaires assessing psychological measures. These were the State-Trait Anxiety Inventory (STAI A and B) to assess state and trait anxiety (Spielberger et al., 1983); the Liebowitz Social Anxiety Scale (LSAS) to assess social anxiety (Liebowitz, 1987); the Beck Depression Inventory (BDI) to assess depression (Beck and Steer, 1987); and the Urgency Premeditation Perseverance and Sensation seeking impulsive behavior scale (UPPS; Whiteside et al., 2003), which is a measure of impulsivity as a personality trait. The UPPS is composed of subscales, one of which describes the difficulty to restrain behavioral reactions in situations that elicit strong emotions (Urgency) (Cirilli et al., 2011). The control of all of these variables is important, as young drinkers with depression, generalized or social anxiety, as well as high impulsivity symptoms have been shown to be at increased risk of AUD during young adulthood (McKenzie et al., 2011; Norberg et al., 2011; Henges and Marczinsky, 2012). Therefore, we can observe that participants of both groups disclosed no difference in terms of these variables (see Table 1).

Based on these criteria, 40 undergraduate students were selected for the fMRI study, and they were classified as light $(n=20)$ or heavy social drinkers $(n=20)$. We obtained informed written consent from the participants after they were fully informed regarding the nature of the study. The local ethics committee of the Brugmann Hospital approved the study ("Comité d'Ethique Hospitalier OM 026”). The participants were instructed to abstain from consuming alcohol 24 hours prior to the 
fMRI sessions, and none of them reported any drinking episodes in the two days prior

to the assessment. Alcohol abstinence before the test was confirmed using AlcoSensor III breath analyzers Alcometer (Alert J5®, Alcohol Countermeasure Systems Corp, 2006), and their urine was tested to control for cannabis use (Tetrahydrocannabinol; Instant-View ${ }^{\circledR}$ MultiDrug Screen Urine Test; Alfa Scientific Designs, Inc.) in the light as well as in the heavy drinkers. Participants were paid 50 euros for their time.

Among these participants, four were found to have reaction times in response to Go trials that were too slow ( 3 s.d. above the mean): they were therefore discarded from final analyses. Among the remaining 36 participants, two (one in each group) were identified as ambidextrous (Robinson, 2013): after running SPM analyses without them, we observed that their inclusion did not affect the laterality of observed brain activations. Therefore, these 36 participants were included in the final sample used for the statistical analyses, with 17 and 19 participants in the light and in the heavy social drinker groups, respectively.

Insert Table 1 about here

\section{The Go/No-go task}

Participants were instructed to press a button with the thumb of their right hand, as fast and as accurately as possible, whenever the letter M (Go) was displayed, and to withhold pressing the button when the letter W (No-Go) was displayed. Responses were made on a commercially available MRI compatible keypad system (fORP; Current Design, Vancouver). Both letters were superimposed on pictorial backgrounds, denoting three different contexts: the neutral context (NC), represented by a black screen; the alcohol-related context (AC), represented by someone holding a glass of beer; and the non-alcohol context (NAC), represented by an empty basket. 
Two fMRI recording sessions were performed. During each session, the order of the three stimulation blocks (NC, AC, and NAC) was similar in Sessions 1 and 2, and this order was counterbalanced across participants. Each block contained 133 letters, divided into 93 Go (70\%) and 40 No-Go (30\%) letters. Go and No-Go letters were displayed in a semi-random order to avoid the consecutive presentation of two No-Go letters within each block. Each block started with the presentation of a background screen (black for $\mathrm{NC}$, or $\mathrm{AC}$ or $\mathrm{NAC} ; 500 \mathrm{~ms}$ ) followed by the letter $\mathrm{M}$ or $\mathrm{W}$ appearing on this background screen for $200 \mathrm{~ms}$, subsequently replaced by a return to the initial background screen for $1,300 \mathrm{~ms}$. Thus, the subjects had up to $1,500 \mathrm{~ms}$ to press the button before the next letter appeared. An interval of 1 minute was taken between each block during a Session; a five minute interval was allowed between Sessions 1 and Session 2. Additional details concerning the task can be found in Petit et al. (2012) (see Figure 1 for illustration).

Insert Figure 1 about here

\section{Procedure}

\section{Behavioral statistical analysis}

Behavioral data were analyzed with repeated measures (ANOVA). Omission error rates (i.e. no response in Go trials), commission error rates (i.e. a key press in No-Go trials), and reaction time (RT) to Go stimuli were analyzed. Simple effects were explored and interaction sources were systematically examined. The Students' ttests, ANOVA, and Bonferroni's post-hoc test were used when appropriate. All analyses were done with SPSS $20^{\circledR}$, and the level of significance was set at 0.05 .

fMRI data acquisition and image analysis

Data were acquired on a Philips Achieva 3T (Philips HealthCare, Best, the Netherlands) using a dynamic axial T2*-sensitive gradient-echo (EPI) sequence 
(TR=3,000 ms (=dynamic scan time); TE=35 ms; flip angle 90; FOV 230 (RL) x 230

(AP) $\mathrm{mm}^{2}$; SENSE acceleration factor 2.9; matrix size 76 x 75; acquisition voxel size: $3.03 \times 3.03 \times 3 \mathrm{~mm}^{3}$ ). For each dynamic volume, a total of 40 contiguous transverse slices were acquired in an interleaved order. Each fMRI session included 220 BOLD volumes and lasted around 12 minutes. Two fMRI sessions were achieved as two consecutive BOLD scans. Anatomical images were obtained using a sagittal 3D T1weighted TFE sequence with an inversion prepulse (TR/TE=9.8/4.6 ms; TI 1,035 ms; TFE shot acquisition: 1,950ms; flip angle $8^{\circ}$; FOV: 200 (FH) x 238 (AP) $\mathrm{mm}^{2}$; matrix size: $228 \times 200$; acquisition voxel size: $0.88 \times 1.19 \times 1.0 \mathrm{~mm}^{3}$; total acquisition time 5min35s). The MR scanner was equipped with the Quasar Dual imaging gradients (maximum amplitude and slew rate: $40 \mathrm{mT} / \mathrm{m}$ and $200 \mathrm{mT} / \mathrm{m} / \mathrm{ms}$ ) and an 8 -channel SENSE head coil.

Functional MRI data were pre-processed and analyzed with SPM8 (Wellcome Department of Cognitive Neurology, London) implemented in MATLAB 7.8 (Mathworks Inc., Sherbom, MA). All the following steps were based on these main following references: Holmes et al., 1997; Friston et al., 1998; 2005. The first five functional volumes in the acquisition were discarded to avoid transient spin saturation effects. Preprocessing for each individual required that functional images were (i) corrected for slice acquisition delays, (ii) realigned to the first volume of the first run to correct for within- and between-run motion, (iii) co-registered with the anatomical scan, (iv) normalized to the MNI template using an affine fourth degree $\beta$-spline interpolation transformation and a voxel size of $2 \times 2 \times 2 \mathrm{~mm}^{3}$ after the skull and bones had been removed with a mask based on the individual anatomical images, and (v) spatially smoothed using a 8-mm full width at half maximum (FWHM) Gaussian kernel. All included subjects had less than $4 \mathrm{~mm}$ of head movement in $x, y$, or $z$ 
directions (a threshold usually reported in fMRI studies literature; e.g., Massat et al., 2012; Murphy et al., 2012). Additionally, it is also current practice (in order to minimize the influence of motion artifacts on group comparisons) to conduct a matching of within scanner movements between groups (e.g., Schillbach et al., 2016). Therefore, the magnitude of head motion at each time point for translation and rotation parameters was obtained for each subject in each session, and averaged within each group. No between-groups difference $(p>.05)$ was evidenced using either the maximum head motion or the mean head motion measurements, indicating similar movement patterns during scanning.

Data were analyzed using a mixed-effects model that aimed to show a stereotypical effect in the population from which the subjects were drawn (Penny and Holmes, 2003). For each subject, a first-level intra-individual analysis was aimed at modeling data to partition observed neurophysiological responses into components of interest, confounds, and error, by using a general linear model (Friston, 2003). For each subject, evoked hemodynamic responses to each event types were modeled with a delta (stick) function corresponding to stimulus presentation (with an explicit duration set to 0 ) convolved with a canonical hemodynamic response function within the context of the general linear model (GLM) (e.g., Jacques et al., 2009). Correct and incorrect responses were modeled separately (e.g., Strange et al., 2005). More precisely, the regressors of interest were built using stick functions separately positioned at the onset of each correct No-go trial (correct No-go trials in NC, AC, NAC) as well as at the onset of all Errors (modeled separately and identified at each button click for the letter "W"). The errors were considered altogether, independently of contexts, due to their small rate (average number of 5.6 to 8.4 errors on 40 trials by context and by session). Movement parameters derived from realignment of the 
functional volumes (translations in $\mathrm{x}, \mathrm{y}$ and $\mathrm{z}$ directions and rotations around $\mathrm{x}, \mathrm{y}$ and regressors were secondarily convolved with the canonical hemodynamic response function. High-pass filtering was implemented in the matrix design using a cut-off period of 128 seconds to remove low drift frequencies from the time series. The two fMRI sessions were modeled separately. Effect of interests were then tested by linear contrasts, generating statistical parametric maps $[\mathrm{SPM}(\mathrm{T})]$. Here, the contrasts of interest searched for significant changes in blood oxygen level-dependent (BOLD) signal associated with correct and incorrect No-go trials (correct No-go trials in NC, AC, and NAC, and all Errors) in both fMRI sessions. Since no inference was made at this fixed effect level of analysis, summary statistic images were thresholded at $p<$ 0.95 (uncorrected). Resulting subject-level contrast images were then spatially smoothed at $6 \mathrm{~mm}$ FWHM Gaussian kernel (Peigneux et al., 2006), and entered in two separate second-level factorial analyses; one for correct trials (correct trials in $\mathrm{NC}$, in $\mathrm{AC}$ and in NAC) and the other one for failed trials (Errors), in which subjects were considered as a random effect (RFX). This second smoothing procedure was performed to increase inter-subject averaging at the group level, taking into account inter-individual anatomical variability. As parameters estimation, contrasts and smoothing are all linear operations, smoothing at the second level permits the overall smoothing kernel to increase in a linear manner. This improves statistical power at the group level while allowing spatially accurate results at the first level (e.g., Boly et al., 2007).

Our first two questions concerned correct inhibitory trials. The first one concerns the impact of different contexts on correct inhibitions, while the second one refers to the neural activity related to correct inhibitions, independently of contexts. 
Similarly to analyses computed on behavioral results, these two questions could be investigated through a full factorial design 2 (Light vs. Heavy) x 3 (NC, AC, NAC), computed to show T-contrasts testing for significant activation changes between groups, for the main effects of contexts and groups $\mathrm{x}$ contexts interactions. A null conjunction analysis was also computed to identify the brain network commonly activated when trials were correctly inhibited at the group level $(\mathrm{N}=36)$, independently of context.

Our third question concerned the neural activity related to failed inhibitions, independently of contexts. Due to the small error rate by context, it was impossible to carry on the full factorial design 2 (Light vs. Heavy) x 3 (NC, AC, NAC). We hence computed a one-sample t-test to assess the neural network related to Errors across all participants $(\mathrm{N}=36)$. Two-sample t-tests were then used to compare related activity in light vs. heavy drinkers.

To conclude, statistical inferences about our three main questions were then obtained after corrections at the voxel level using Gaussian random field theory (Worsley, 1996) at $\mathrm{p}^{\text {corr }}<0.05$ corrected for multiple comparisons in the whole brain volume.

\section{Results}

\section{Behavioral data}

Three main analyses were performed to analyze this task by way of an analysis of variance (ANOVA; 3 × 2 mixed factorial design) with 'Context' (NC, AC, NAC) as the within-subject factor and 'Group' (light; heavy) as the between-subject factor. The data are summarized in Table 2 . 
Firstly, we checked the speed of response (RTs) in the Go trials. The results did not reveal a main Group effect $(p=0.831)$ nor a Group x Context interaction $(p=$ $0.634)$, but a main effect of Context was observed $[\mathrm{F}(2,68)=8.607, p=0.001$; etasquared $=0.202$, observed power $=0.944$, suggesting that RTs in the Go trials during NC blocks were faster than during NAC ones (post hoc Bonferroni t-tests: NC Go vs. NAC Go: 322 vs. 334 ms, $p=0.002$; NC Go vs. AC Go: 322 vs. 330 ms, $p=0.063$; AC Go vs. NAC Go: 330 vs. 334 ms, $p=0.240)$.

We also examined whether both groups were equivalent in their performance in terms of responding to Go trials. No significant statistical group effect emerged ( $p$ $>0.175$ ), probably due to a ceiling effect (i.e. a mean performance of $99 \%$ correct in both groups).

The final analysis concerned commission errors, i.e. the rate of inhibition errors (the key press in No-go trials). A main effect of Context emerged $[\mathrm{F}(2,68)=5.679, p=0.007$; eta-squared $=0.143$, observed power $=0.813]$. Post hoc Bonferroni t-tests showed that the rate of errors is more substantial in NC compared to AC $(p=0.003)$ and NAC $(p=0.042)$, while AC and NAC did not differ $(p=1)$. However, the number of errors is not modulated by Group (main group effect: $\mathrm{F}(1.34)=1.698, p=0.201$; interaction Group x Context: $\mathrm{F}(2.68)=0.379, p=0.661)$, suggesting that the rate of commission errors is similar in light and heavy drinkers, irrespective of contexts.

Overall, the behavioral data suggested that light and heavy social drinkers performed the Go/No-go task equally, as indexed by a similar amount of correct inhibitions as well as of commission errors, irrespective of contexts (see Table 2). Importantly, hit rates on Go trials did not differ between groups. Indeed, it is wellknown that when participants tend to respond more rapidly, they also tend to exhibit 
decreased accuracy in No-go trials (Jonker et al., 2013). In the present study, however, the absence of group difference on commission errors did not seem to be due to a "protective" slowing of the RT in Go trials.

\section{Insert Table 2 about here}

\section{fMRI data}

(1) Is there an effect of context?

We computed a full factorial design 2 (Light vs. Heavy) x 3 (NC, AC, NAC) analysis. Firstly, we checked for specific activations related to correct No-go trials when each context was specifically envisaged on the whole sample $(\mathrm{N}=36)$. The NC context involved a widespread neural activity, including bilateral frontal inferior, right middle temporal regions, right angular and left inferior parietal regions. Activations of left-lateralized frontal inferior, angular, middle temporal, and frontal superior areas were disclosed during the AC context. In regard to the NAC context, activity was shown in bilateral angular regions, in bilateral inferior and left superior frontal areas, and left inferior temporal regions. When compared through T-contrasts for the whole sample, these contexts (NC vs. AC-NAC; AC vs. NC-NAC; NAC vs. NC-AC) did not reveal any supra-threshold results (neither for corrected $\mathrm{p}<0.05$ nor for uncorrected $\mathrm{p}<0.001$; cluster extent $\geq 100$ ). Similarly, looking at between-population differences for contexts (T-contrasts NC light vs. NC heavy; AC light vs. AC heavy; NAC light vs. NAC heavy; NC heavy vs. NC light; AC heavy vs. AC light; NAC heavy vs. NAC light) did not reveal any supra-threshold results (for corrected $\mathrm{p}<0.05$, as well as for uncorrected $\mathrm{p}<0.001$; cluster extent $\geq 100$ ). Lastly, a null conjunction analysis on the whole sample revealed that, independently of the type of contexts, correct inhibitions 
involve a neural network encompassing left angular and left inferior frontal regions across all participants (see Table 3 and Figure 2).

Insert Figure 2 and Table 3 about here

\section{(2) Are there any group differences for correct inhibitions?}

Based always on the full factorial design, when all correct trials were considered independently of the context, T-contrast looking at between-group differences (NCAC-NAC correct light vs. NC-AC-NAC correct heavy) did not reveal any suprathreshold results (for corrected $\mathrm{p}<0.05$ as well as for uncorrected $\mathrm{p}<.001$; cluster extent $\geq 100$ ) for the light or for the heavy drinkers.

\section{(3) Are there any group differences for failed inhibitions?}

A one sample t-test on all of the participants $(\mathrm{N}=36)$ revealed that, independently of the type of contexts (as the ratio of errors was too small in separate contexts to allow for specific analyses), failed inhibitions involve a widely distributed neural network involving right anterior cingulate, inferior frontal and inferior parietal regions as well as left superior temporal and angular areas (see Table 4 and Figure 3). Looking at between-population differences, our two sample t-test analysis disclosed a network of regions showing an increased BOLD response to failed trials which differed considerable for the groups. On the one hand, light drinkers displayed higher BOLD activity in the right inferior frontal, right middle cingulate, and left superior temporal regions. On the other hand, heavy drinkers exhibited higher BOLD activity in the left superior occipital, left caudate, left amygdale, and right cerebellum areas.

Insert Figure 3 and Table 4 about here 


\section{Discussion}

While there have been a few studies (Squeglia et al., 2011; Squeglia et al., 2012; Xiao et al., 2013) linking heavy social drinking with decreased performance, as compared to light drinkers, most studies using ERPs or fMRI found evidence for neural differences indexing compensation mechanisms, without any behavioral modification (reviewed by Petit et al., 2014). In the present study, we found that even though light and heavy drinkers displayed a similar performance level in a visual Go/No-go task, specific brain activations were detected, mainly for failed inhibitions, when groups were compared.

A first set of analyses allowed us to check for activations observable in all of the participants when they achieved correct RI in different contexts $(\mathrm{NC}, \mathrm{AC}$, and NAC). Any supra-threshold significant data were not seen when t-contrasts were performed between contexts (across all participants) nor when between-group differences were examined separately for each context. This suggests that, in our experiment, context is not strong enough to elicit BOLD signal modulation in light and heavy social drinkers.

A second set of analyses aimed at investigating whether, independently of context, correct inhibitions can elicit different brain activations in light versus heavy drinkers. A conjunction analysis revealed that, when they achieved correct inhibitions, all participants activated their left inferior frontal regions as well as their left angular gyrus. Activation of the right inferior frontal cortex (rIFC) has been consistently linked with RI (Aron et al., 2004; Chambers et al., 2009; Bari and Robbins, 2013), although the involvement of the left IFC has also been reported (Swick et al., 2008), indicating that sometimes activation has also been observed bilaterally (Menon et al., 2001; Watanabe et al., 2002; Cai and Leung, 2011). A role for the left angular gyrus 
cannot be directly associated with executive functioning. Rather, the left angular gyrus is known to be engaged in phonological short-term memory and mathematical problem solving. Participants may therefore at times have employed a verballymediated calculation strategy to respond to the Go/No-go task, instead of exerting executive control (Mahmood et al., 2013). Though yet again, light and heavy drinkers did not elicit different brain regions to achieve correct inhibitions. This could index a still efficient cognitive control mechanism, that could therefore be envisaged as a "protective factor against dependence". Indeed, despite their profile as heavy consumers of alcohol (i.e. a mean of $12 \pm 5.6$ alcohol doses per week), our participants cannot be considered as alcohol dependent patients, as suggested by a mean AUDIT score below the cut-off score of 20 (as AUDIT scores of above 20 clearly warrant further diagnostic evaluation for alcohol dependence; Babor et al., 1994) and the fact that recently detoxified alcoholic patients who were confronted to a similar task in our laboratory (Petit et al., 2014) disclosed a mean AUDIT score of 32.

The most important results of the present study were obtained, however, when failed inhibitions (independently of context) were considered. We were able to show that all participants activated a widely distributed neural network, involving the rACC, rIFC, right inferior parietal as well as left angular and left pole temporal superior (STS) regions, when they commit errors. Aside from activations already found with correct inhibitions, related to executive control (rIFC) and verbal strategy (left angular gyrus) processes, specific activations were also revealed across all of the participants when an error was committed. In this view, rACC activations are probably the well-documented ones. Indeed, a well-established finding is that the ACC transiently activates in association with the commission of errors (Botvinick et 
al., 2004), serving as a generic "error detector" (Braver et al., 2001) that may trigger compensatory adjustment mechanisms necessary to adjust one's own action (Vocat et al., 2008). Among the other activations, the inferior parietal lobe seems to be more involved in visual-spatial attention (Behrmann et al., 2004), while activation of left temporal regions has repeatedly been reported to occur in successive discrimination and temporal comparisons of simple visual attributes, as engaged in our visual Go/Nogo involving the discrimination of letter "M" and "W" (De Zubicaray et al., 2000), suggesting its implication in selective attention mechanisms (Stevens et al. 2000). Overall, when the failed inhibitions of all of the participants were considered, the data of the present study confirmed earlier results suggesting that IFC is a key brain region responsible for inhibitory motor control; while the mesial prefrontal cortex, including the ACC, in conjunction with the inferior parietal lobe, form a neural network for error detection (Rubia et al., 2003; 2005; 2007). Above all, by controlling for behavioral performance, the main relevance of the present study was that it allowed for comparison of the neural networks subtending a same amount of correct and failed inhibitions in light and heavy social drinkers. In this view, while neural differences between groups for correct inhibitions could not be discerned, the main results of the present study were in regard to BOLD group differences observed in response to failed inhibitions, as these differences were highly significant ( $\mathrm{p}$ corr $<0.05$, cluster extent $\geq 100$ ). Indeed, compared to heavy drinkers, light drinkers disclosed enhanced activations in the rIFC, right middle cingulate (rMCC) and the left STS during errors, while, inversely, heavy drinkers exhibited the most pronounced activations in the left occipital superior, left amygdale, and left caudate areas, as well as the right cerebellum. In other words, we observed that, while light and heavy drinkers committed the same number of errors, the underlying neural networks for these errors 
were entirely different. On the one hand, we were able to document that light drinkers exhibited activations in regions mediating response inhibition (rIFC; Chambers et al., 2009), motor response selection (rMCC; Braver et al., 2001) as well as in regions associated with the prediction of actions based on past actions (left STS; Choudhury et al., 2006). Indeed, the MCC, corresponding to the rostral cingulate motor area (Picard and Strick, 1996), is known to undergo enhanced activation during error processing (Braver et al., 2001; Garavan et al., 2003; Nee et al., 2011), triggering environmental monitoring and response selection mechanisms (Taylor et al., 2009). On the other hand, we were able to document that heavy social drinkers exhibited activations in regions devoted to movement control (as cerebellar activity has been linked to the processing of error signals that could be used for improving performance; Ernst et al., 2002), to pro-active slowing (as the function to slow responses to favor successful no-go trials has been related to the caudate nucleus; Boelher et al., 2010), to the enhanced visual computing that occurs during inhibitory control (which engaged left superior occipital regions; Leroux et al., 2006) and to emotional conflict processing (left amygdala; Etkin et al., 2006).

All together, these data appear to indicate that, while light drinkers disclosed an "executive-based" neural response to errors (e.g. planning future actions through RI and motor response selection; “Next time I should not click on W"), heavy drinkers are more engaged in a "visually-driven emotional strategy" (e.g. planning future motor action by enhancing visual processes of the salient stimuli, decreasing hit rate to Go trials in order to avoid the negative emotion triggered by a failed response; such as "Oh no, it was not the letter M"). Overall, at the structural level, brain atrophy associated with chronic alcohol consumption is a common finding, with enlarged ventricles and sulci as well as generalized loss of volume in cortical gray matter, 
white matter, cerebellum and subcortical structures (e.g., Pfefferbaum et al., 1992). Longitudinally, deformation-based morphometry confirmed tissue recovery (mainly in focal parts of the fronto-ponto-cerebellar circuit) in recovering alcoholics who maintain long-term sobriety (e.g., Cardenas et al., 2007). It is intriguing to wonder whether these brain abnormalities may have predated drug-taking, rendering individuals vulnerable for the development of dependence. Abnormalities in frontostriatal brain systems implicated in self-control in both stimulant-dependent individuals and their biological siblings who have no history of chronic drug abuse have been found and may indicate markers of neural vulnerability for pathological habits in drug addiction typically resulting in compulsive drug-taking behaviors when prefrontal control fails to regulate behavior (e.g., Ersche et al., 2012). In addition, the physiological correlates of the effects of alcohol on the brain have been examined with a range of techniques, with most suggesting that acute alcohol consumption results in numerous brain changes, including increases in cerebral blood flow (CBF) (e.g., Schuckit et al., 1988). CBF increases with alcohol were less prominent in individuals who required more drinks to experience alcohol-related effects (showing a low response -LR- to alcohol), this relationship indexing a robust marker of an enhanced risk for future alcohol problems (e.g., Tolentino et al., 2011). Also, at the functional level, the role of neural alterations in cognitive control mechanisms (reviewed by Luijten et al., 2014) as well as of error awareness (Garavan and Stout, 2005) in triggering addictions has become widely accepted. Tasks that are often used to measure inhibitory control are the go/no-go task and the stop signal reaction time task (SSRT), a test that measures the ability to stop a response that has already been initiated thanks to a warning cue (see Goldstein and Volkow, 2011 for a review). Consuming alcohol is known to impair inhibitory skills as well as error processing, as 
in go/no-go tasks (e.g., Easdon et al., 2005) than in SSRT (e.g., Li et al., 2009). Yet neural differences in the inhibitory circuitry observable before the initiation of heavy drinking may, however, predict the onset of substance abuse (Wetherill et al., 2013). Clearly, the present study did not allow us to determine whether neural differences observed with failed inhibitions were due to neural predispositions (i.e. present before the onset of alcohol drinking) and/or to alcohol consumption. However, by comparing healthy participants engaged in light vs. heavy social drinking habits, our study appears to indicate that, while the neural network necessary to achieve correct inhibitions is similar across participants, the neural network subtending commission errors is completely different in light vs. heavy drinkers. The "rationale-executive" neural response of light drinkers contrasted with the more "visual-perceptiveemotional" reaction of heavy drinkers. We suggest that these neural differences subtending error processing could index an "impaired insight" at the functional level that may lead patients to deny the severity of their illness, thereby contributing to the transition to addiction as well as to addiction persistence (Goldstein et al., 2009). Future longitudinal fMRI studies (comparable to Wetherill and colleagues' study (2013)) should be envisaged to investigate whether young social drinkers displaying this pattern of neural activity to failed inhibitions are actually at a higher risk to develop long-term alcohol abuse. In this view, participants with low vs. high responsiveness to alcohol (LR vs. HR groups) should also be taken into account in further studies. Indeed, for instance, Schuckit and colleagues (2012) showed through a SSRT that, despite similar group task performance, LR group demonstrated relatively less, whereas the HR group demonstrated more, error- and inhibition- related BOLD activations. These data suggest a brain mechanism that may contribute to how a low 
responsiveness to alcohol might enhance the risk for future heavy drinking and alcohol dependence.

In conclusion, we are fully aware that our study suffers from some limitations. For instance, the present results have to be cautiously considered due to small sample size and further studies should involve larger samples in order to test for reproducibility of our data (Button et al., 2013). Besides including LR and HR participants, larger samples would also allow investigating for sex influence. Indeed, (1) men are consistently more than twice as likely as women to report chronic heavy drinking (e.g. Meyer et al.,2000); and (2) gender differences in regional brain activation to response inhibition have been highlighted in a fMRI study (Ray Li et al., 2006), suggesting that, during RI, men activated the motor circuitry while women appeared to involve visual association or habit learning. It could therefore be highly relevant to reproduce the current study with higher samples of females and males in order to investigate for possible sex differences. Another limitation refers to the fact that some authors prefer to use an extremely difficult situation of inhibitory control in a challenging stop task by using an algorithm that adjusts the task individually so that each subject only succeeds in half of all the stop trials, while failing in the other half (Rubia et al., 2003; 2005; 2007). This allows computation of contrasts between an equal number of correct and failed inhibitions in order to separate brain activation related to successful motor response inhibition and to inhibition failure or error detection (Rubia et al., 2003). In the present study, we used a simpler Go/No-go task (Criaud and Boulinguez, 2013), which by controlling task accuracy allows the same number of trials (correct or failed) between groups to be compared. Further studies should use more complex inhibitory tasks to investigate whether (i) this would affect the behavioral performances of social drinkers; and (ii) this would have a specific 
impact on the neural network devoted to correct and failed inhibitions. Also, the use of a more complex task could allow more errors to be triggered, thus allowing examination of the neural networks devoted to errors in different contexts. Indeed, in the present study, we reduced error to a unique condition, mainly due to the small ratio. However, while some studies reported no impact of an alcohol-related context on correct/failed inhibitions (Nederkoorn et al., 2009; Houben et al., 2012; Mainz et al., 2012; Petit et al., 2014), others were able to show higher commission error rates, as alcohol-related cues are supposed to grab attention and decrease inhibitory skills (Greeley et al., 1993; Cox et al., 1999; Herrmann et al., 2001; Noël et al., 2005; Bartholow et al., 2007; 2010; Stacy and Wiers, 2010). Moreover, in the present study, behavioral data showed that a higher rate of commission errors could be seen in NC compared to AC and NAC in all of the participants, while it could be expected that by grabbing attention, contextual no-go trials may be more difficult to inhibit. A possible explanation could be that, due to a better visual contrast of the letters displayed on the black screen, NC context triggered faster RTs to Go trials and then a higher rate of commission errors (e.g., Dhar et al., 2011). We therefore suggest that further studies should use other forms of experimental designs, by adapting the current go/no-go task (no NC context? individual feedback to speed responses to Go trials?) or by using a SSRT (e.g., Verbruggen and Logan, 2008). Indeed, besides classical go and go-go stimuli, using SSRT would allow by including stop warning signals to investigate for proactive control strategies (that relies upon the anticipation and prevention of interference before it occurs) as well as for reactive control strategies (that relies upon the detection and resolution of interference after its onset). As both can be differently affected in pathological populations (Aron, 2011; Verbruggen et al., 2012; Pani et al., 2013), such a design may be particularly well-suited to investigate whether the neural 
networks devoted to correct and failed inhibitions may be modulated by contexts that may or may not be related to alcohol.

\section{Conclusions}

The main finding of the present study is that, even though light and heavy drinkers exhibited a similar level of performance in a Go/No-go task, they displayed involvement of very different neural networks to failed inhibitions. Such neural differences in the absence of behavioral modification are typical findings when heavy social drinkers are compared to light ones (reviewed by Petit et al., 2014). According to a 'functional compensation view', decreases or absences in activation reflect deficits in brain function, and the concomitant increases in activation reflect 'attempted' or 'successful' compensation for these deficits (Pfefferbaum et al., 2001). Clearly, it remains unclear whether these different activations reflect the recruitment of different regions and processes indexing different strategies (assuming that regional process-specificity does not change with alcohol consumption), and/or alterations in the processes mediated by the recruited regions (as a result of neural plasticity and regional changes in process-specificity due to alcohol consumption). However, as clear previous fMRI data indicate that (1) altered inhibitory mechanisms may predict the future onset of substance abuse (Wetherill et al., 2013), and (2) impaired insight has a key-role in drug abuse development and persistence, the data obtained in the present study suggests that the different networks subtending inhibitory errors in light and heavy drinkers may be considered as vulnerability factors that may subtend the transition from a controlled heavy consumption behavior to a state of dependence. Further longitudinal studies designed to test this hypothesis are warranted. 


\section{Acknowledgments}

Salvatore Campanella is Research Associate at the Fund of Scientific Research (FRSFNRS, Belgium). Mathieu Bourguignon benefits of a research grant from the FRIA (FRS-FNRS, Belgium). Xavier De Tiège is "Postdoctorate Clinical Master Specialist" at the Fund of Scientific Research (FRS-FNRS, Belgium).

\section{Compliance with Ethical Standards:}

\section{Disclosure: Funding/Conflict of interest}

This study was financially supported by the Fund of Scientific Research (Research Grant J.0009.13, FRS-FNRS, Belgium). The authors have no competing financial interest, potential conflict of interest, or financial relationship with commercial entities to report. They are funded by the Belgian Fund for Scientific Research (F.N.R.S., Belgium), but this fund did not exert any editorial direction or censorship on any part of this article.

\section{Ethical approval}

All procedures performed in studies involving human participants were in accordance with the ethical standards of the institutional and/or national research committee and with the 1964 Helsinki declaration and its later amendments or comparable ethical standards.

Informed consent was obtained from all individual participants included in the study. 


\section{References}

Albert, J., Lopez-Martın, S., Carretié, L. (2010). Emotional context modulates response inhibition: neural and behavioral data. Neuroimage, 49, 914-921.

Aron, A., Robbins, T., Poldrack, R. (2004). Inhibition and the right inferior frontal cortex. Trends in Cognitive Sciences, 8: 170-177.

Aron A. From reactive to proactive and selective control: developing a richer model for stopping inappropriate responses. Biol Psychiatry 2011, 69: 55-68.

Babor, T., Campbell, R., Room, R., Saunders, J. (1994). Lexicon of Alcohol and Drug Terms. World Health Organization, Geneva.

Babor, T., Higgins-Biddle, J. (2001). Brief intervention for hazardous and harmful drinking: a manual for use in primary care. World Health Organization, Department of Blood Safety and Clinical Technology.

Bari, A., Robbins, T. (2013). Inhibition and impulsivity: behavioral and neural basis of response control. Progress in Neurobiology, 108, 44-79.

Bartholow, B., Henry, E., Lust, S. (2007). Effects of alcohol sensitivity on P3 event-related potential reactivity to alcohol cues. Psychology of Addictive Behavior 21: $555-563$.

Bartholow, B., Lust, S., Tragesser, S. (2010.) Specificity of P3 event-related potential reactivity to alcohol cues in individuals low in alcohol sensitivity. Psychology of Addictive Behavior, 24, 220-228.

Beck, A.T., Steer, R.A. (1987). Beck Depression Inventory Manual. 1st ed. San Antonio: Psychological Corporation.

Behrmann, M., Geng, J. J., Shomstein, S. (2004). Parietal cortex and attention. Current Opinion in Neurobiology, 14(2), 212-217. 
Boehler, C. N., Appelbaum, L. G., Krebs, R. M., Hopf, J. M., Woldorff, M. G. (2010). Pinning down response inhibition in the brain - conjunction analyses of the stop-signal task. Neuroimage, 52(4), 1621-1632.

Boly, M., Coleman, M. R., Davis, M. H., Hampshire, A., Bor, D., Moonen, G., et al. (2007). When thoughts become action: an fMRI paradigm to study volitional brain activity in non-communicative brain injured patients. Neuroimage, 36(3), 979992.

Bonomo, Y.A., Bowes, G., Coffey, C., Carlin, J.B., Patton, G.C. (2004). Teenage drinking and the onset of alcohol dependence: a cohort study over seven years. Addiction 99: 1520-1528.

Botvinick, M. M., Cohen, J. D., Carter, C. S. (2004). Conflict monitoring and anterior cingulate cortex: an update. Trends in Cognitive Sciences, 8(12), 539-546.

Bradley, K. A., Bush, K. R., Epler, A. J., Dobie, D. J., Davis et al. (2003). Two brief alcohol-screening tests From the Alcohol Use Disorders Identification Test (AUDIT): validation in a female Veterans Affairs patient population. Archives of Internal Medicine, 163(7), 821-829.

Braver, T. S., Barch, D. M., Gray, J. R., Molfese, D. L., Snyder, A. (2001). Anterior cingulate cortex and response conflict: effects of frequency, inhibition and errors. Cerebral Cortex, 11(9), 825-836.

Bush, K., Kivlahan, D. R., McDonell, M. B., Fihn, S. D., Bradley, K. A. (1998). The AUDIT alcohol consumption questions (AUDIT-C): an effective brief screening test for problem drinking. Archives of internal medicine, 158(16), 17891795.Button, K. S., Ioannidis, J. P., Mokrysz, C., Nosek, B. A., Flint, J., et al. (2013). Power failure: why small sample size undermines the reliability of neuroscience. Nature Reviews Neuroscience, 14(5), 365-376. 
Cai, W., Leung, H. C. (2011). Rule-guided executive control of response inhibition: functional topography of the inferior frontal cortex. PloS one, 6(6), e20840.

Campanella, S., Peigneux, P., Petit, G., Lallemand, F., Saeremans, M., Noël, X. et al. (2013). Increased cortical activity in binge drinkers during working memory task: a preliminary assessment through a functional magnetic resonance imaging study. PloS one, 8(4), e62260.

Campbell, A.M.G., Evans, M., Thomson, J.L.G., Williams, M.J. (1971). Cerebral atrophy in young cannabis smokers. Lancet 298: 1219-1224.

Cardenas, V. A., Studholme, C., Gazdzinski, S., Durazzo, T. C., Meyerhoff, D. J. (2007). Deformation-based morphometry of brain changes in alcohol dependence and abstinence. Neuroimage, 34(3), 879-887.

Carretié, L., Hinojosa, J.A., Albert, J., Mercado, F. (2006). Neural response to sustained affective visual stimulation using an indirect task. Experimental Brain Research, 174: 630-637.

Chambers, C., Garavan, H., Bellgrove, M. (2009). Insights into the neural basis of response inhibition from cognitive and clinical neuroscience. Neuroscience and Biobehavioral Reviews, 33: 631-646.

Chassin, L., Pitts, S.C., Prost, J. (2002) Binge drinking trajectories from adolescence to emerging adulthood in a high-risk sample: predictors and substance abuse outcomes. Journal of Consulting and Clinical Psychology, 70(1):67-78.

Choudhury, S., Blakemore, S. J., Charman, T. (2006). Social cognitive development during adolescence. Social Cognitive and Affective Neuroscience, 1(3), 165-174. 
Cirilli, L., de Timary, P., Lefèvre, P., Missal, M. (2011). Individual differences in impulsivity predict anticipatory eye movements. PlosOne 10: e26699.

Cox, W.M., Yeates, G.N., Regan, C.M. (1999). Effects of alcohol cues on cognitive processing in heavy and light drinkers. Drug and Alcohol Dependence, 55: 85-89.

Crego, A., Holguín, S.R., Parada, M., Mota, N., Corral, M., Cadaveira, F. (2009). Binge drinking affects attentional and visual working memory processing in young university students. Alcoholism: Clinical Experimental Research, 33, 18701879.

Crego, A., Rodriguez-Holguín, S., Parada, M., Mota, N., Corral, M., Cadaveira, F. (2010) Reduced anterior prefrontal cortex activation in young binge drinkers during a visual working memory task. Drug and Alcohol Dependence, 109: $45-56$.

Crego, A., Cadaveira, F., Parada, M., Corral, M., Caamaño-Isorna, F., Rodriguez-Holguín, S. (2012) Increased amplitude of P3 event-related potential in young binge drinkers. Alcohol 46: 415-425.

Crews, F.T., Buckley, T., Dodd, P.R., Ende, G., Foley, H., Harper, C., et al. (2005). Alcoholic Neurobiology: Changes in Dependence and Recovery. Alcoholism: Clinical Experimental Research, 29: 1504-1513.

Criaud, M., \& Boulinguez, P. (2013). Have we been asking the right questions when assessing response inhibition in go/no-go tasks with fMRI? A meta-analysis and critical review. Neuroscience \& biobehavioral reviews, 37(1), 11-23.

De Zubicaray, G. I., Andrew, C., Zelaya, F. O., Williams, S. C. R., \& Dumanoir, C. (2000). Motor response suppression and the prepotent tendency to respond: a parametric fMRI study. Neuropsychologia, 38(9), 1280-1291. 
Dhar M, Wiersema JR, Pourtois G. Cascade of Neural Events Leading from Error Commission to Subsequent Awareness Revealed Using EEG Source Imaging. PLoS ONE 2011, 6(5): e19578.

Easdon, C., Izenberg, A., Armilio, M L., Yu, H, Alain, C (2005). Alcohol consumption impairs stimulus-and error-related processing during a Go/No-Go Task. Cognitive Brain Research, 25(3), 873-883.

Ehlers CL, Phillips E, Finnerman G, Gilder D, Lau P, and Criado J. (2007) P3 components and adolescent binge drinking in Southwest California Indians. Neurotoxicol Teratol, 29: 153-163.

Ernst, M., Bolla, K., Mouratidis, M., Contoreggi, C., Matochik, J. A., Kurian, et al. (2002). Decision-making in a risk-taking task: a PET study. Neuropsychopharmacology 26, 682-691.

Ersche, KD, Jones, PS, Williams, GB, Turton, AJ, Robbins, TW, Bullmore, ET (2012). Abnormal brain structure implicated in stimulant drug addiction. Science, 335(6068), 601-604.

Etkin, A., Egner, T., Peraza, D. M., Kandel, E. R., Hirsch, J. (2006). Resolving emotional conflict: a role for the rostral anterior cingulate cortex in modulating activity in the amygdala. Neuron, 51(6), 871-882.

Field M., Kiernan A., Eastwood B., Child R. Rapid approach responses to alcohol cues in heavy drinkers. J Behav Ther Exp Psychiatry 2008;39:209-218.

Friston KJ, Buechel C, Fink GR, Morris J, Rolls E, Dolan RJ. (1997). Psychophysiological and modulatory interactions in neuroimaging. Neuroimage, 6(3), 218-229. 
Friston, K. J., Fletcher, P., Josephs, O., Holmes, A., Rugg, M. D., \& Turner,

R. (1998). Event-related fMRI: characterizing differential responses. NeuroImage, 7(1), 30-40.

Friston K (2003). Introduction: experimental design and statistical parametric mapping. In: Frackowiak R, Friston K, Frith C, Dolan R, Price C, Zeki S, Ashburner J, Penny W, editors. Human Brain Function. London: Academic Press.

Friston, K. J., Stephan, K. E., Lund, T. E., Morcom, A., \& Kiebel, S. (2005). Mixed-effects and fMRI studies. NeuroImage, 24(1), 244-252.

Garavan, H., Ross, T. J., Kaufman, J., Stein, E. A. (2003). A midline dissociation between error-processing and response-conflict monitoring. Neuroimage, 20(2), 1132-1139.

Garavan, H., \& Stout, J. C. (2005). Neurocognitive insights into substance abuse. Trends in cognitive sciences, 9(4), 195-201.

Gitelman, D. R., Penny, W. D., Ashburner, J., Friston, K. J. (2003). Modeling regional and psychophysiologic interactions in fMRI: the importance of hemodynamic deconvolution. Neuroimage, 19(1), 200-207.

Greeley JD, Swift W, Prescott J, Heather N (1993) Reactivity to alcoholrelated cues in heavy and light drinkers. J Stud Alcohol 54: 359-368.

Goldstein, R. Z., Volkow, N. D., Wang, G. J., Fowler, J. S., Rajaram, S. (2001). Addiction changes orbitofrontal gyrus function: involvement in response inhibition. Neuroreport, 12(11), 2595.

Goldstein, R. Z., Bechara, A., Garavan, H., Childress, A. R., Paulus, M. P., Volkow, N. D. (2009). The neurocircuitry of impaired insight in drug addiction. Trends in cognitive sciences, 13(9), 372-380. 
Goldstein, R. Z., Volkow, N. D. (2011). Dysfunction of the prefrontal cortex in addiction: neuroimaging findings and clinical implications. Nature Reviews Neuroscience, 12(11), 652-669.

Hall GH (1970) Effects of nicotine and tobacco smoke on the electrical activity of the cerebral cortex and olfactory bulb. Brit J Pharmacol 38: 271-286.

Henges, A. L., Marczinski, C. A. (2012). Impulsivity and alcohol consumption in young social drinkers. Addictive behaviors, 37(2), 217-220.

Herrmann MJ, Weijers HG, Wiesbeck GA, Böning J, Fallgatter AJ (2001) Alcohol cue-reactivity in heavy and light social drinkers as revealed by event-related potentials. Alcohol Alcohol 36: 588-593.

Hermens DF, Lagopoulos J, Tobias-Webb J, De Regt T, Dore G, et al (2013). Pathways to alcohol-induced brain impairment in young people: A review. Cortex 49(1): 3-17.

Holmes, A., Poline, J. B., \& Friston, K. (1997). Characterizing brain images with the general linear model. In R. Frackowiak, K. Friston, C. Frith, R. Dolan \& J. C. Mazziotta (Eds.), Human brain function (pp. 59-84). farde London: Academic Press.

Houben, K., Havermans, R. C., Nederkoorn, C., Jansen, A. (2012). Beer à No-Go: Learning to stop responding to alcohol cues reduces alcohol intake via reduced affective associations rather than increased response inhibition. Addiction, 107(7), 1280-1287.

Jacques, P. L. S., Dolcos, F., \& Cabeza, R. (2009). Effects of aging on functional connectivity of the amygdala for subsequent memory of negative pictures a network analysis of functional magnetic resonance imaging data. Psychological science, 20(1), 74-84. 
Jonker T, Seli P, Cheyne J, Smilek D. Performance reactivity in a continuousperformance task: Implications for understanding post-error behavior. Conscious Cogn 2013, 22: 1468--1476.

Leroux, G., Joliot, M., Dubal, S., Mazoyer, B., Tzourio-Mazoyer, N., Houdé, O. (2006). Cognitive inhibition of number/length interference in a Piaget-like task in young adults: Evidence from ERPs and fMRI. Human brain mapping, 27(6), 498-509.

Li, C. S., Luo, X., Yan, P., Bergquist, K., Sinha, R. Altered impulse control in alcohol dependence: neural measures of stop signal performance. Alcohol. Clin. Exp. Res. 33, 740-750 (2009).

Liebowitz, M. R. (1987). Social phobia (pp. 141-173). Karger Publishers.

Luijten, M., Machielsen, M. W., Veltman, D. J., Hester, R., Haan, L. D., Franken, I. H. (2014). Systematic review of ERP and fMRI studies investigating inhibitory control and error processing in people with substance dependence and behavioural addictions.

López-Caneda E, Cadaveira F, Crego A, Gómez-Suárez A, Corral M, et al. (2012) Hyperactivation of right inferior frontal cortex in young binge drinkers during response inhibition: a follow-up study. Addiction 107: 1796-1808.

Mainz, V., Drüke, B., Boeker, M., Kessel, R., Gauggel, S., Forkmann, T. Influence of cue exposure on inhibitory control and brain activation in patients with alcohol dependence. Front Hum Neurosci, 2012;6: 1-13.

Mahmood, O. M., Goldenberg, D., Thayer, R., Migliorini, R., Simmons, A. N., Tapert, S. F. (2013). Adolescents' fMRI activation to a response inhibition task predicts future substance use. Addictive behaviors, 38(1), 1435-1441. 
Maurage, P., Pesenti, M., Philippot, P., Joassin, F., Campanella, S. (2009) Latent deleterious effects of binge drinking over a short period of time revealed only by electrophysiological measures. J Psychiatry Neurosci, 34, 111-118.

Maurage P, Joassin F, Speth A, Modave J, Philippot P, et al. (2012) Cerebral effects of binge drinking: respective influences of global alcohol intake and consumption pattern. Clin Neurophysiol 123: 892-901.

Massat, I., Slama, H., Kavec, M., Linotte, S., Mary, A., Baleriaux, D., et al. (2012). Working memory-related functional brain patterns in never medicated children with ADHD. PloS one, 7(11), e49392.

McGue M (1994) Genes, environment, and the etiology of alcoholism. In: Zucker R, Boyd G, Howard J, editors. The Development of Alcohol Problems: Exploring the Biopsychosocial Matrix of Risk (NIAAA Research Monograph No. 26). US Government Printing Office; Washington, DC: pp 1-40.

McKenzie M, Jorm AF, Romaniuk H, Olsson CA, Patton, GC (2011): Association of adolescent symptoms of depression and anxiety with alcohol use disorders in young adulthood: findings from the Victorian Adolescent Health Cohort Study. Med J Aust 195: 27-30.

Menon, V., Adleman, N. E., White, C. D., Glover, G. H., Reiss, A. L. (2001). Error-related brain activation during a Go/NoGo response inhibition task. Human brain mapping, 12(3), 131-143.

Meyer, C., Rumpf, H.J., Hapke, U., Dilling, H., John, U. (2000).Prevalence of alcohol consumption, abuse and dependence in a country with high per capita consumption: findings from the German TACOS study. Transitions in Alcohol Consumption and Smoking. Social Psychiatry and Psychiatric Epidemiology 35 (12),539-547. 
Murphy, E. R., Foss-Feig, J., Kenworthy, L., Gaillard, W. D., \& Vaidya, C. J. (2012). Atypical functional connectivity of the amygdala in childhood autism spectrum disorders during spontaneous attention to eye-gaze. Autism research and treatment, 2012.

Nederkoorn, C., Baltus, M., Guerrieri, R., Wiers, R. W. (2009). Heavy drinking is associated with deficient response inhibition in women but not in men. Pharmacology Biochemistry and Behavior, 93(3), 331-336.

Nee, D. E., Kastner, S., Brown, J. W. (2011). Functional heterogeneity of conflict, error, task-switching, and unexpectedness effects within medial prefrontal cortex. Neuroimage, 54(1), 528-540.

Nicolas JM, Estruch R, Salamero M, Orteu N, Fernandez-Sola J, et al (1997) Brain impairment in well-nourished chronic alcoholics is related to ethanol intake. Ann Neurol 41: 590-598.

Noël, X., Van der Linden, M., d'Acremont, M., Colmant, M., Hanak, C., et al. (2005). Cognitive biases toward alcohol-related words and executive deficits in polysubstance abusers with alcoholism. Addiction, 100(9), 1302-1309.

Norberg, MN, Oliver, J, Alperstein, DM, Zvolensky, MJ, Norton, AR (2011). Adverse consequences of student drinking: The role of sex, social anxiety, drinking motives. Addict Behav 36: 821-828.

Norman, A. L., Pulido, C., Squeglia, L. M., Spadoni, A. D., Paulus, M. P., Tapert, S. F. (2011). Neural activation during inhibition predicts initiation of substance use in adolescence. Drug and alcohol dependence, 119(3), 216-223.

Oldfield, R.C. (1971). The assessment and analysis of handedness: the Edinburgh Inventory. Neuropsychologia 9: 97-113. 
Pani P, Menghini D, Napolitano C, et al. Proactive and reactive control of movement are differently affected in Attention Deficit Hyperactivity Disorder children. Res Dev Disabil 2013, 34: 3104-3111.

Peigneux, P., Orban, P., Balteau, E., Degueldre, C., Luxen, A., Laureys, S., et al. (2006). Offline persistence of memory-related cerebral activity during active wakefulness. PLoS Biol. 4, e100.

Penny, W., Holmes, A. (2003). Random-effect analysis. In: Frackowiak R, Friston K, Frith C, Dolan R, Price C, Zeki S, Ashburner J, Penny W, editors. Human Brain Function. London: Academic Press.

Petit, G., Kornreich, C., Noël, X., Verbanck, P., Campanella, S. (2012). Alcohol-Related Context Modulates Performance of Social Drinkers in a Visual Go/No-Go Task: a Preliminary Assessment of Event-Related Potentials. PlosOne, 7(5), e37466.

Petit, G., Cimochowska, A., Kornreich, C., Hanak, C., Verbanck, P., Campanella, S. (2014). Neurophysiological correlates of response inhibition predict relapse in detoxified alcoholic patients: some preliminary evidence from event-related potentials. Neuropsychiatric Disease and Treatment, 10, 1025-1037.

Petit, G., Maurage, P., Kornreich, C., Verbanck, P., Campanella, S. (2014). Binge drinking in adolescents: a review of neurophysiological and neuroimaging research. Alcohol and alcoholism, 49(2), 198-206.

Pfefferbaum, A., Lim, K.O., Zipursky, R.B., Mathalon, D.H., Rosenbloom, et al. (1992). Brain gray and white matter volume loss accelerates with aging in chronic alcoholics: a quantitative MRI study. Alcohol Clin Exp Res 16 (6), 1078-1089. 
Pfefferbaum A, Desmond JE, Galloway C, Menon V, Glover GH, et al. (2001) Reorganization of frontal systems used by alcoholics for spatial working memory: an fMRI study. NeuroImage 14:7-20.

Picard, N., Strick, P. L. (1996). Motor areas of the medial wall: a review of their location and functional activation. Cerebral cortex, 6(3), 342-353.

Ray Li C, Huang C, Constable T, Sinha R. Gender differences in the neural correlates of response inhibition during a stop signal task. NeuroImage 2006, 32 : 1918-1929.

Ridderinkhof, K.R., de Vlugt, Y., Bramlage, A., Spaan, M., Elton, M., et al. (2002). Alcohol consumption impairs detection of performance errors in mediofrontal cortex. Science 298: 2209-2211.

Robinson, J. (2013). Edinburgh Handedness Inventory. In Encyclopedia of Autism Spectrum Disorders (pp. 1051-1054). Springer New York.

Rogers, R. D., Robbins, T. W. (2001). Investigating the neurocognitive deficits associated with chronic drug misuse. Current opinion in neurobiology, 11(2), 250-257.

Rubia, K., Smith, A. B., Brammer, M. J., Taylor, E. (2003). Right inferior prefrontal cortex mediates response inhibition while mesial prefrontal cortex is responsible for error detection. Neuroimage, 20(1), 351-358.

Rubia, K., Smith, A. B., Brammer, M. J., Toone, B., Taylor, E. (2005). Abnormal brain activation during inhibition and error detection in medication-naive adolescents with ADHD. American Journal of Psychiatry, 162(6), 1067-1075.

Rubia, K., Smith, A. B., Taylor, E., \& Brammer, M. (2007). Linear age-correlated functional development of right inferior fronto-striato-cerebellar 
networks during response inhibition and anterior cingulate during error-related processes. Human brain mapping, 28(11), 1163-1177.

Saunders JB, Aasland OG, Babor TF, de la Fuente JR, Grant M (1993) Development of the Alcohol Use Disorders Identification Test (AUDIT): WHO Collaborative Project on Early Detection of Persons with Harmful Alcohol Consumption--II. Addiction 88: 791-804.

Schuckit, MA., Tapert, S, Matthews, SC, Paulus, MP, Tolentino, NJ, et al. (2012). fMRI differences between subjects with low and high responses to alcohol during a stop signal task. Alcoholism: Clinical and Experimental Research, 36(1), 130-140.

Schuckit MA, Gold EO. A simultaneous evaluation of multiple markers of ethanol/placebo challenges in sons of alcoholics and controls. Arch Gen Psychiatry. $1988 ; 45: 211-216$.

Schweinsburg, A. D., Paulus, M. P., Barlett, V. C., Killeen, L. A., Caldwell, L. C., Pulido, C., et al. (2004). An FMRI study of response inhibition in youths with a family history of alcoholism. Annals of the New York Academy of Sciences, 1021(1), 391-394.

Schweinsburg AD, McQueeny T, Nagel BJ, Eyler LT, Tapert SF (2010) A preliminary study of functional magnetic resonance imaging response during verbal encoding among adolescent binge drinkers. Alcohol 44: 111-7.

Schweinsburg, A.D., Schweinsburg, B.C., Nagel, B.J., Eyler, L.T., Tapert, S.F. (2011) Neural correlates of verbal learning in adolescent alcohol and marijuana users. Addiction 106: 564-573.

Schilbach, L., Hoffstaedter, F., Müller, V., Cieslik, E. C., Goya-Maldonado, R., Trost, S., et al. (2016). Transdiagnostic commonalities and differences in resting 
state functional connectivity of the default mode network in schizophrenia and major depression. NeuroImage: Clinical, 10, 326-335.

Smith, LA, Foxcroft, DR (2009). The effect of alcohol advertising, marketing and portrayal on drinking behaviour in young people: systematic review of prospective cohort studies. BMC Public Health 9: 51.

Smith, J. L., Mattick, R. P. (2013). Evidence of deficits in behavioural inhibition and performance monitoring in young female heavy drinkers. Drug and alcohol dependence, 133(2), 398-404.

Spielberger CD (1983) Manual for the State-Trait Anxiety Inventory (STAI). Consulting Psychologists Press, Palo Alto, CA.

Squeglia, LM, Schweinsburg, AD, Pulido, C, Tapert, SF (2011) Adolescent binge drinking linked to abnormal spatial working memory brain activation: differential gender effects. Alcohol Clin Exp Res 35: 1831-1841.

Squeglia LM, Pulido C, Wetherill RR, Jacobus J, Brown GG, and Tapert SF. (2012) Brain response to working memory over three years of adolescence: influence of initiating heavy drinking. J Stud Alcohol Drugs 73(5): 749-760.

Stacy AW, Wiers RW (2010) Implicit cognition and addiction: a tool for explaining paradoxical behavior. Annu Rev Clin Psychol 6: 551-575.

Stevens, A. A., Skudlarski, P., Gatenby, J. C., Gore, J. C. (2000). Eventrelated fMRI of auditory and visual oddball tasks. Magnetic resonance imaging, 18(5), 495-502.

Strange, B. A., Hurlemann, R., Duggins, A., Heinze, H. J., Dolan, R. J. (2005). Dissociating intentional learning from relative novelty responses in the medial temporal lobe. Neuroimage, 25(1), 51-62. 
Swick, D., Turken, U. (2002). Dissociation between conflict detection and error monitoring in the human anterior cingulate cortex. Proceedings of the National Academy of Sciences, 99(25), 16354-16359.

Swick, D., Ashley, V., Turken, U. (2008). Left inferior frontal gyrus is critical for response inhibition. BMC neuroscience, $9(1), 1$.

Taylor, K. S., Seminowicz, D. A., Davis, K. D. (2009). Two systems of resting state connectivity between the insula and cingulate cortex. Human brain mapping, 30(9), 2731-2745.

Tolentino, NJ, Wierenga, CE, Hall, S, Tapert, SF, Paulus, MP, et al. (2011). Alcohol effects on cerebral blood flow in subjects with low and high responses to alcohol. Alcoholism: Clinical and Experimental Research, 35(6), 1034-1040.

Verbruggen, F., Logan, G. D. (2008). Response inhibition in the stop-signal paradigm. Trends in cognitive sciences, 12(11), 418-424.

Verbruggen F, Logan G. Automaticity of cognitive control: Goal priming in response-inhibition paradigms. J Exp Psychol 2009, 35(5): 1381-1388.

Verbruggen F, Adams R, Chambers C. Proactive motor control reduces monetary risk taking in gambling. Psychol Sci 2012, 23: 805-815.

Viner RM, Taylor B. (2007) Adult outcomes of binge drinking in adolescence: findings from a UK national birth cohort. J Epidemiol Community Health 61(10):902-907.

Vocat, R., Pourtois, G., Vuilleumier, P. (2008). Unavoidable errors: a spatiotemporal analysis of time-course and neural sources of evoked potentials associated with error processing in a speeded task. Neuropsychologia, 46(10), 2545-2555. 
Volkow, N. D., Fowler, J. S., Wang, G. J., Swanson, J. M. (2004). Dopamine in drug abuse and addiction: results from imaging studies and treatment implications. Molecular psychiatry, 9(6), 557-569.

Watanabe, J., Sugiura, M., Sato, K., Sato, Y., Maeda, Y., Matsue, Y., et al. (2002). The human prefrontal and parietal association cortices are involved in NO-GO performances: an event-related fMRI study. Neuroimage, 17(3), 1207-1216.

Wetherill, R. R., Squeglia, L. M., Yang, T. T., Tapert, S. F. (2013). A longitudinal examination of adolescent response inhibition: neural differences before and after the initiation of heavy drinking. Psychopharmacology, 230(4), 663-671.

Whiteside S.P., Lynam D.R. Understanding the role of impulsivity and externalizing psychopathology in alcohol abuse: application of the UPPS impulsive behavior scale. Exp Clin Psychopharmacol 2003;11:210-217.

Worsley KJ (1996) A unified statistical approach for determining significant signals in images of cerebral activation. Hum Brain Mapp 4: 58-73.

Xiao, L., Bechara, A., Gong, Q., Huang, X., Li, X., Xue, G., et al. (2013). Abnormal affective decision making revealed in adolescent binge drinkers using a functional magnetic resonance imaging study. Psychology of Addictive Behaviors, 27(2), 443. 


\section{Figure Captions}

Figure 1 - Go/No-Go task. Participants were confronted with 2 sessions of three blocks of 133 stimuli, divided in 93 Go trials (letter M), and 40 No-Go trials (letter W). The letters were superimposed on a long-lasting black background (No Context; NC); a non-alcohol-related background picture (NAC), and an alcohol-related background picture (AC).

Figure 2 - Through a full-factorial analysis, sagittal views with specific activations for the whole sample $(\mathrm{N}=36)$ were disclosed for each separate context (NC, AC, NAC). Brain areas activated for both groups across all contexts (null conjunction analysis) were also displayed ( $\mathrm{p}<.05$ corrected; for all x, y, z coordinates details, see Table 3).

Figure 3 - Sagittal and coronal views of brain areas activated in response to failed inhibitory trials in the whole sample $(\mathrm{N}=36$; One Sample t-test) were displayed. Group differences in brain activations to errors (Light vs. Heavy; Heavy vs. Light) were highlighted thanks to two-sample t-tests $(\mathrm{p}<.05$ corrected; for all $\mathrm{x}, \mathrm{y}, \mathrm{z}$ coordinates details, see Table 4). 

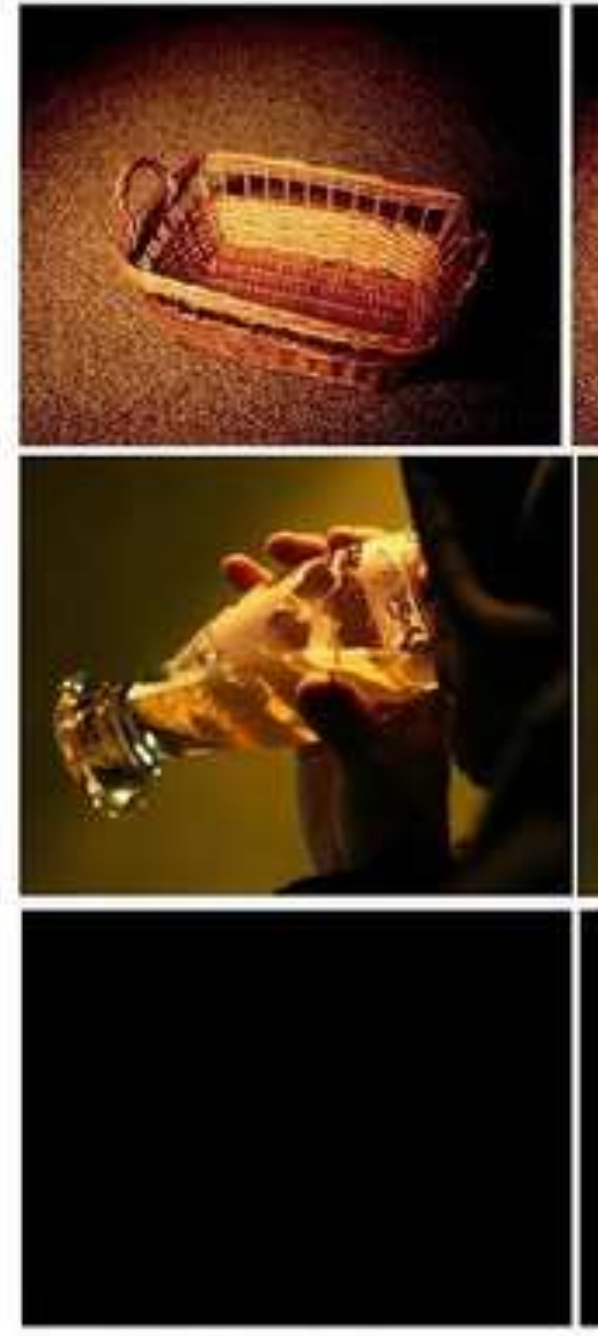

Start of the task $500 \mathrm{~ms}$
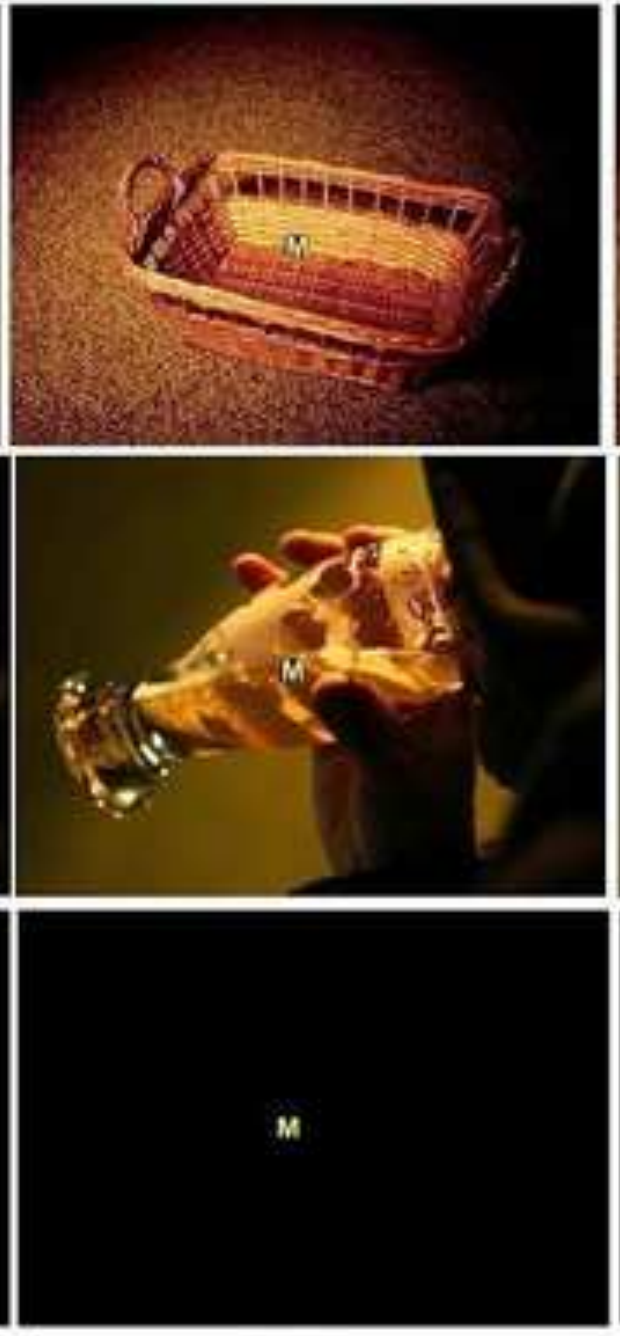

$200 \mathrm{~ms}$

Go Trials
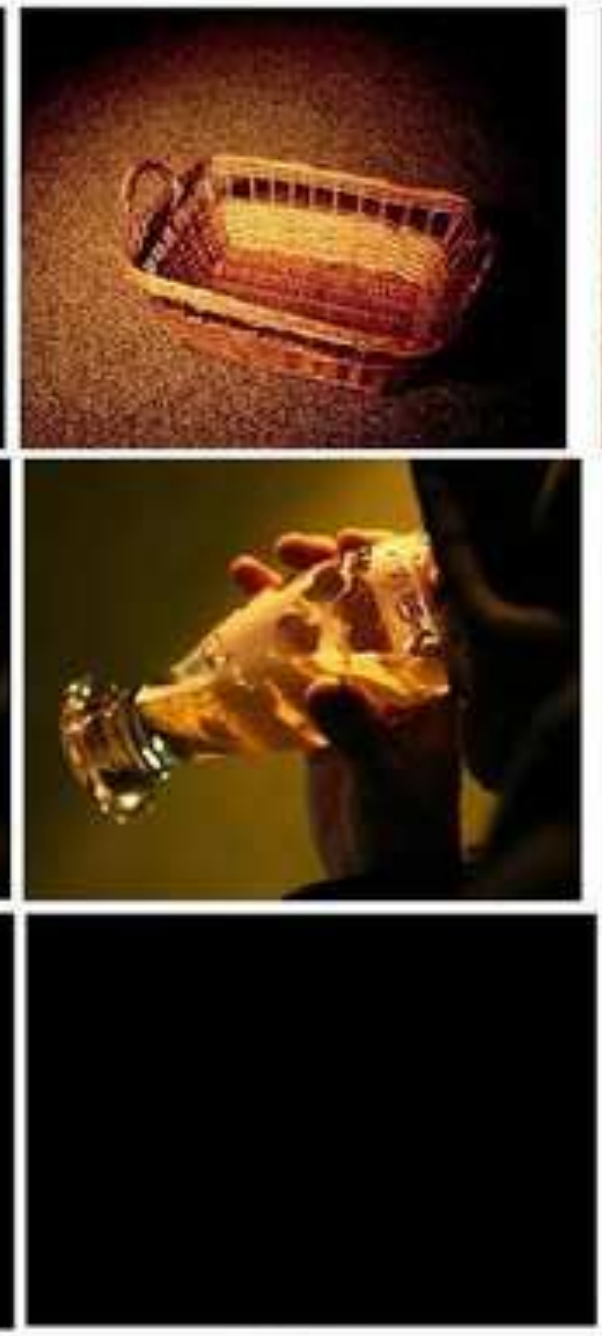

$1300 \mathrm{~ms}$

W

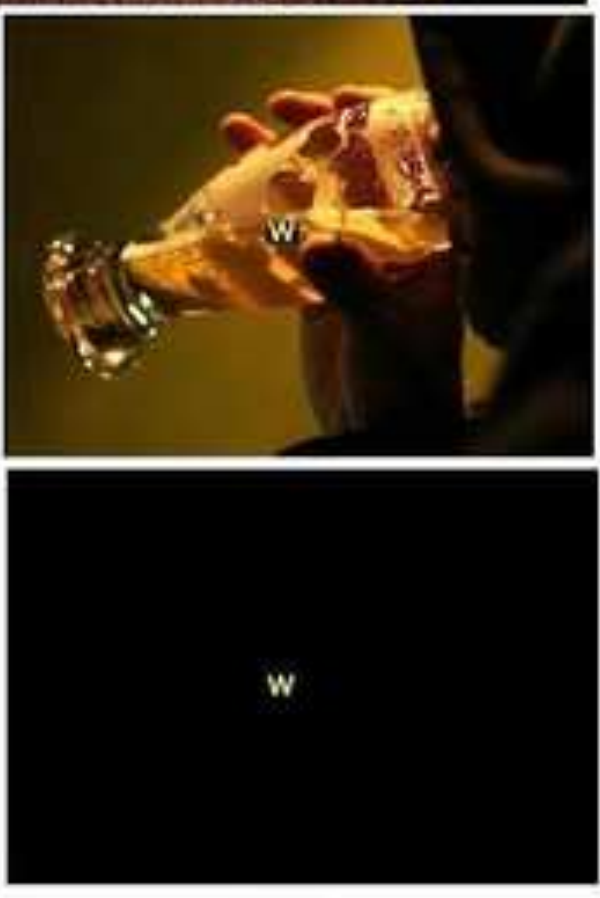

$200 \mathrm{~ms}$

NoGo Trials
NAC 


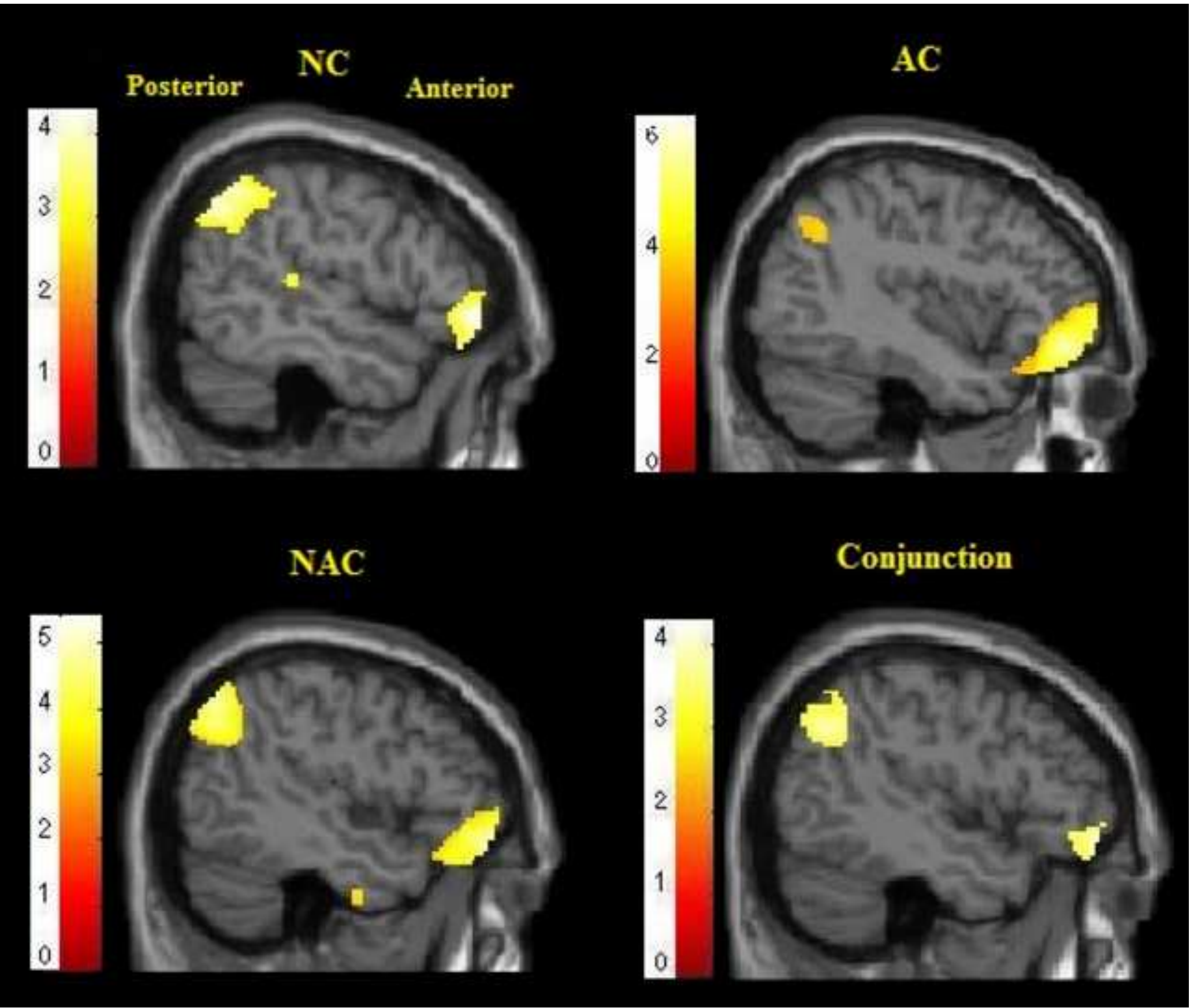




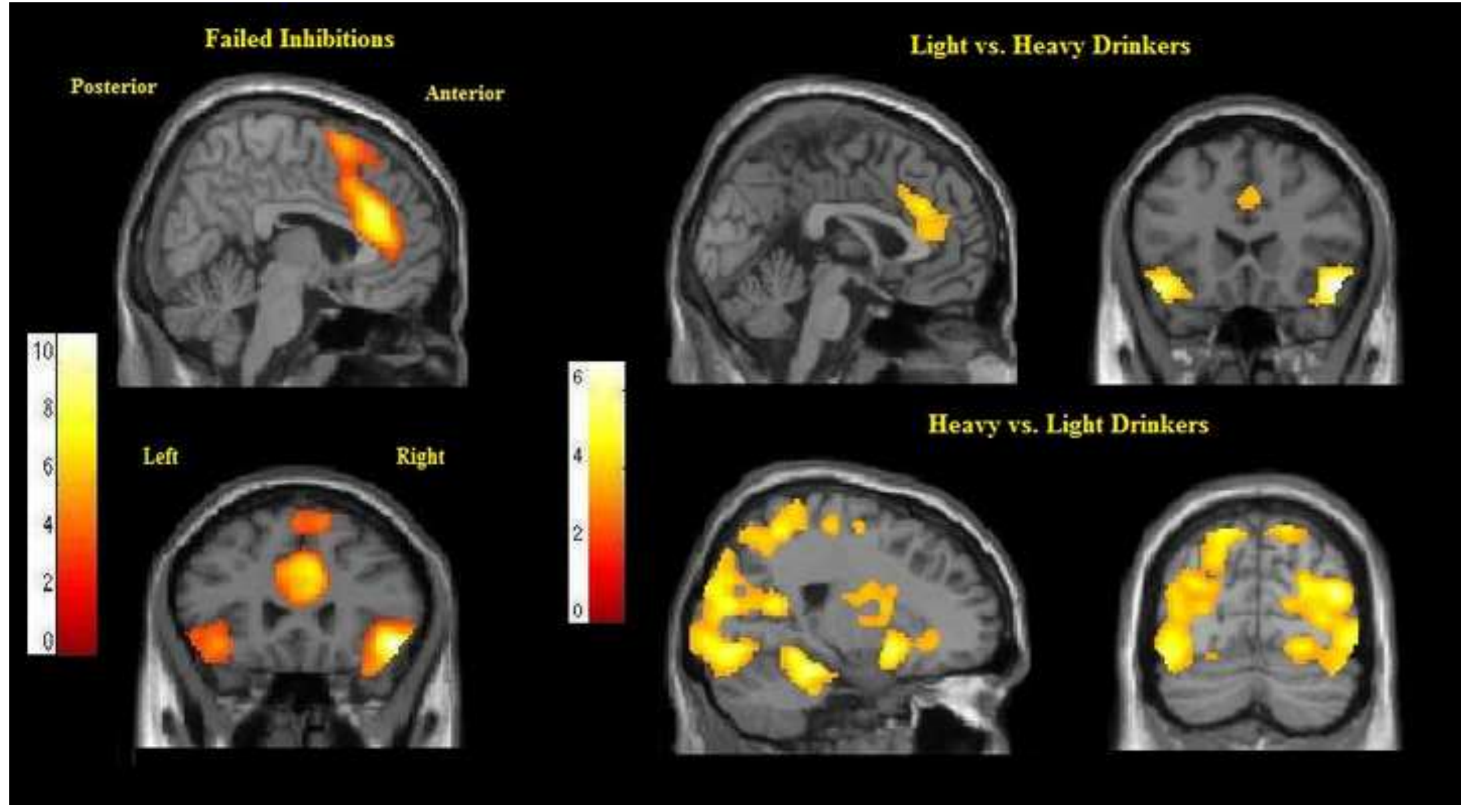




\begin{tabular}{|c|c|c|}
\hline & $\begin{array}{c}\text { Light } \\
\text { drinkers } \\
(\mathbf{n}=17)\end{array}$ & $\begin{array}{c}\text { Heavy } \\
\text { drinkers } \\
(n=19)\end{array}$ \\
\hline Gender $(\delta: P)\left(\chi^{2}(1)=.071 ; p=.790\right)$ & $7: 10$ & $7: 12$ \\
\hline Family history of alcoholism (No:Yes) $\left(\chi^{2}(1)=.390 ; p=.532\right)$ & $14: 3$ & $14: 5$ \\
\hline Age $($ year $)(t(34)=.942 ; p=.353)$ & $25.8 \pm 4.2$ & $24.7 \pm 3$ \\
\hline Level of education (years) $(t(34)=-.275 ; p=.785)$ & $15.2 \pm 2.2$ & $15.4 \pm 1.9$ \\
\hline Right handedness (Oldfield Inventory) $(\mathrm{t}(34)=-.536 ; \mathrm{p}=.596)$ & $82.3 \pm 24$ & $86 \pm 13$ \\
\hline AUDIT $(\mathrm{t}(34)=-10.533 ; \mathrm{p}<.001)^{*}$ & $3.2 \pm 2.2$ & $17 \pm 3$ \\
\hline AUDIT-C (t (34) $=-9.219 ; \mathrm{p}<.001)^{*}$ & $2.9 \pm 1.9$ & $7.8 \pm 1.3$ \\
\hline Number of alcohol doses per week $(t(34)=-7.459, p<.001)^{*}$ & $1.5 \pm 1.5$ & $12 \pm 5.6$ \\
\hline BDI $(\mathrm{t}(34)=-.626 ; \mathrm{p}=.535)$ & $6.3 \pm 5.8$ & $7.5 \pm 5.5$ \\
\hline STAI State $(\mathrm{t}(34)=-.926 ; \mathrm{p}=.361)$ & $45.2 \pm 9.5$ & $47.9 \pm 7.7$ \\
\hline STAI Trait $(\mathrm{t}(34)=.133 ; \mathrm{p}=.895)$ & $45.5 \pm 11.1$ & $45 \pm 10.1$ \\
\hline Liebowitz $\underline{\text { SAS }}(\mathrm{t}(34)=.113 ; \mathrm{p}=.911)$ & $35.4 \pm 18.4$ & $34.7 \pm 14.3$ \\
\hline UPPS Total $(\mathrm{t}(34)=.230 ; \mathrm{p}=.820)$ & $105 \pm 11.9$ & $104 \pm 12.7$ \\
\hline UPPS - Urgency subscale $(\mathrm{t}(34)=.359 ; \mathrm{p}=.722)$ & $32.9 \pm 5$ & $32.2 \pm 6$ \\
\hline
\end{tabular}

Table 1 - The results are expressed as number, or mean \pm SD. AUDIT: Alcohol Use Disorder Identification Test: score of 0 indicate total abstinence, scores from 1 to 7 refer to light drinking, scores starting a 8 define hazardous drinking while scores from 20 to 40 indexed a possible dependence; BDI: Beck Depression Inventory: scores between 0 and 4 were used on the BDI to signify absence of depression while people with scores between 8 and 15 displayed a subclinical level of moderate depression; STAI: State and Trait Anxiety Inventory: STAI scores group the participants as follows: less than 36: very low; 36-45: low; 46-55: normal; 56-65: high; more than 65: very high.; SAS: Social Anxiety Scale: high social anxiety individuals were defined as those scoring 65 or more on the SAS and the low social anxiety individuals were defined as those scoring 50 or below on that scale; UPPS: Urgency Premeditation Perseverance and Sensation seeking impulsive behavior scale: higher scores indicate a higher level of impulsivity, the range for the Urgency subscale being [17-46]. * Significant results at $\mathrm{p}<.001$. 


\begin{tabular}{|c|c|c|c|c|c|c|}
\hline & \multicolumn{3}{|c|}{ Light } & \multicolumn{3}{c|}{ Heavy } \\
\cline { 2 - 7 } Go RTs (ms) & NC & AC & NAC & NC & AC & NAC \\
\hline $\begin{array}{c}322 \\
(30)\end{array}$ & 333 & $(29)$ & $(21)$ & $(40)$ & $(41)$ & $(37)$ \\
\hline $\begin{array}{c}\text { Go performance: } \\
\text { mean number on } \\
\text { correct trials (score } \\
\text { on 93) }\end{array}$ & 91.7 & 92.3 & 92.4 & 92.4 & 92.4 & 92.6 \\
\hline $\begin{array}{c}\text { Commission errors: } \\
\text { mean number of } \\
\text { failed trials (score } \\
\text { on 40) }\end{array}$ & $\begin{array}{c}(1.6) \\
(3.6)\end{array}$ & $(1.2)$ & $(0.8)$ & $(1.3)$ & $(1.6)$ & $(0.8)$ \\
\hline
\end{tabular}

Formatted Table

Formatted: Font: $14 \mathrm{pt}$

Formatted: Font: $14 \mathrm{pt}$

Formatted: Font: $14 \mathrm{pt}$

Table 2 - Behavioral data: mean correct response time on Go trials, mean number of correct response to Go

trials by session and mean number of commission errors by session $( \pm$ SD $)$ for Light and Heavy drinkers. 


\begin{tabular}{|c|c|c|c|c|}
\hline $\begin{array}{c}\text { MNI Coordinates } \\
(\mathbf{x}, \mathbf{y}, \mathbf{z})\end{array}$ & Anatomical Area & $\begin{array}{c}\text { K } \\
\text { (Cluster extent) }\end{array}$ & $\begin{array}{c}\mathbf{p}(\mathbf{F W E}) \\
\text {-corr }\end{array}$ & $\begin{array}{c}\text { Peak Z } \\
\text { score }\end{array}$ \\
\hline $\begin{array}{c}\text { Correct Inhibitions } \\
\text { NC }\end{array}$ & & & & \\
\hline $48-6042$ & Right Angular_Gyrus & 825 & .002 & 4.52 \\
\hline $5050-4$ & Right Frontal Inferior Cortex & 734 & .003 & 4.62 \\
\hline$-46-5640$ & Left Parietal Inferior Cortex & 550 & .012 & 3.90 \\
\hline $62-26-2$ & Right Middle Temporal Gyrus & 349 & .056 & 3.89 \\
\hline$-4452-12$ & Left Frontal Inferior Cortex & 358 & .052 & 4.26 \\
\hline $\begin{array}{c}\text { Correct Inhibitions } \\
\text { AC }\end{array}$ & & & & \\
\hline$-5036-18$ & Left Frontal Inferior Cortex & 1167 & .000 & 5.56 \\
\hline$-50-6644$ & Left Angular_Gyrus & 857 & .001 & 5.14 \\
\hline$-66-26-14$ & Left Middle Temporal Gyrus & 428 & .029 & 4.15 \\
\hline-165634 & Left Frontal Superior Cortex & 356 & .053 & 3.60 \\
\hline $\begin{array}{c}\text { Correct Inhibitions } \\
\text { NAC }\end{array}$ & & & & \\
\hline$-4046-14$ & Left Frontal Inferior Cortex & 1225 & .000 & 4.92 \\
\hline-44644 & Left Frontal Superior Cortex & 2840 & .000 & 4.31 \\
\hline$-50-6842$ & Left Angular_Gyrus & 657 & .005 & 4.54 \\
\hline $50-6644$ & Right Angular_Gyrus & 414 & .033 & 4.01 \\
\hline $3644-16$ & Right Front Inferior Cortex & 517 & .015 & 4.02 \\
\hline$-66-22-18$ & Left Temporal Inferior Cortex & 370 & .047 & 5.10 \\
\hline \hline Correct Inhibitions & & & & \\
\hline Conjunction & & 423 & .031 & 3.83 \\
\hline$-50-6838$ & Left Angular_Gyrus & & .061 & 4.26 \\
\hline$-4452-12$ & Left Frontal Inferior Cortex & 338 & & \\
\hline & & & & \\
\hline
\end{tabular}

Formatted Table

Formatted: Font: 9 pt

Table 3 - Brain networks involved in correct inhibitions for the whole sample $(\mathrm{N}=36)$. Coordinates $\mathrm{x}, \mathrm{y}, \mathrm{z}(\mathrm{mm})$ are given in Montreal Neurological Institute (MNI) standard stereotactic space. All results are significant at the voxel level $\mathrm{p}<.05$ corrected; only those in italics disclosed marginally significant data ( $\leq \leq .061$ corrected). 


\begin{tabular}{|c|c|c|c|c|}
\hline $\begin{array}{c}\text { MNI } \\
\text { Coordinates } \\
(\mathbf{x}, \mathbf{y}, \mathbf{z})\end{array}$ & Anatomical Area & $\begin{array}{c}\mathbf{K} \\
\text { (Cluster extent) }\end{array}$ & $\begin{array}{c}\mathbf{p}(\mathbf{F W E}) \\
\text {-corr }\end{array}$ & $\begin{array}{c}\text { Peak Z } \\
\text { score }\end{array}$ \\
\hline Failed Inhibitions & & & & \\
\hline 43426 & Right Anterior-Cingulate_ Cortex & 3926 & .000 & 6.59 \\
\hline $4826-10$ & Right Frontal Inferior Cortex & 3641 & .000 & 7.22 \\
\hline$-4418-14$ & Left Temporal Pole Superior & 1785 & .000 & 6.14 \\
\hline $58-4250$ & Right Parietal Inferior & 990 & .001 & 4.86 \\
\hline$-58-6032$ & Left Angular Gyrus & 346 & .055 & 3.96 \\
\hline $\begin{array}{c}\text { Two-sample t tests } \\
\text { Activations }\end{array}$ & & & & \\
\hline Light vs. Heavy & & & & \\
\hline $5022-14$ & Right Frontal Inferior Cortex & 883 & .001 & 5.36 \\
\hline$-4818-16$ & Left Temporal Pole Superior & 696 & .002 & 5.29 \\
\hline 83030 & Right Middle Cingulate_ Gyrus & 869 & .001 & 4.27 \\
\hline Heavy vs. Light & & & & \\
\hline $18-36-20$ & Right Cerebellum & 25277 & .000 & 5.40 \\
\hline$-26-92$ 22 & Left Occipital Superior Gyrus & & & 5.34 \\
\hline$-144-14$ & Left Amygdala & 2781 & .000 & 5.01 \\
\hline$-26-626$ & Left Caudate Nucleus & 290 & .072 & 4.87 \\
\hline
\end{tabular}

Formatted: Centered

Formatted Table

Formatted: Font: $8 \mathrm{pt}$

Table 4 - Brain networks involved in failed inhibitions. Coordinates $\mathrm{x}, \mathrm{y}, \mathrm{z}(\mathrm{mm})$ are given in Montreal

Neurological Institute (MNI) standard stereotactic space. All results are significant at the voxel level $\mathrm{p}<.05$

corrected; only one in italics disclosed marginally significant data $(\mathrm{p} \leq .072$ corrected) 


\begin{tabular}{|l|l|l|l|l|l|}
\hline MNI Corrdinates & Anatomieal Areat & $\begin{array}{l}\text { K } \\
\text { (Cluster } \\
\text { extent) }\end{array}$ & $\begin{array}{l}\text { FWE } \\
\text {-corr }\end{array}$ & $\begin{array}{l}\text { FDR- } \\
\text { corr }\end{array}$ & $\begin{array}{l}\text { Peak Z } \\
\text { seore }\end{array}$ \\
\hline $\begin{array}{l}\text { PPI (4 34 26) } \\
\text { Activations }\end{array}$ & & & & & \\
\hline 42 30-24 & Right Front Inf & 150 & .207 & .686 & 4.23 \\
\hline $\begin{array}{l}\text { PPI Tw-samplet tests } \\
\text { Activations }\end{array}$ & & & & & \\
\hline Light vs. Heavy & & & & & \\
\hline $16-32$ 12 & Right Hippocampus & 26 & .932 & .437 & 4.04 \\
\hline $28-228$ & Right Front Inf & 35 & .879 & .437 & 3.70 \\
\hline$-18-62$ 26 & Left Cuneus & 40 & .844 & .437 & 3.61 \\
\hline$-20-4028$ & Left Mid Cingulate & 14 & .980 & .478 & 3.21 \\
\hline Heavy vs. Light & & & & & \\
\hline$-626-32$ & Left Cerebellum & 22 & .952 & .689 & 3.82 \\
\hline$-16-40-36$ & Left Cerebellum & 60 & .690 & .689 & 3.73 \\
\hline$-48-22-8$ & Left Temp Mid & 20 & .960 & .689 & 3.56 \\
\hline$-46-3852$ & Left Pariet Inf & 10 & .990 & .689 & 3.32 \\
\hline
\end{tabular}

\begin{tabular}{ll|}
\hline & Formatted: Left \\
\hline & Formatted: Left \\
\hline & Formatted: Left \\
\hline & Formatted: Left \\
\hline & Formatted: Left \\
\hline & Formatt: Left \\
\hline & Formatted: Left \\
\hline
\end{tabular}

Table 5-Results obtained for the PPI centered on the rACC ( $x: 4 \mathrm{y}: 34 \mathrm{z}: 26)$. Coordinates $\mathrm{x}, \mathrm{y}, \mathrm{z}$ (mm) are given in Montreal Neurological Institute (MNI) standard stereotactic space. All results are significant at the voxel level $p<0.001$ uncorrected. Thresholds of false discovery rate (FDR) were then reported in order that readers have a precise idea of prevalence of false positives for these uncorrected data. 